\title{
The employment of people with mental illness
}

\section{Geoff Waghorn ${ }^{1}$ and Chris Lloyd ${ }^{2}$}

\author{
1. Policy and Economics Group, Queensland Centre for Mental Health Research (QCMHR), \\ School of Population Health, University of Queensland, Australia
}

\author{
2. Division of Occupational Therapy, School of Health and Rehabilitation Sciences, \\ University of Queensland, Australia
}

\begin{abstract}
People with a mental illness are among the most socially and economically marginalised members of the community. They experience high levels of unemployment and nonparticipation in the labour force. Unemployment has a number of negative effects including the loss of purpose, structure, roles and status and a sense of identity which employment brings. Employment enables social inclusion in the wider community and is an important way that people with a mental illness can meaningfully participate in the wider community. Australia has a mental health strategy, which guides the ongoing reform of mental health services. However, specific strategies to address the social and economic marginalisation of people with a mental illness have not been addressed. A recovery-oriented approach is recommended, which integrates the key sectors involved. To date there has been little intersectoral collaboration between the various sectors such as mental health services, housing, and vocational services. People require more role-specific assistance to enable them to participate in socially valued roles implicit with citizenship. There is a need to formulate improved pathways to assistance and more evidence-based forms of assistance to re-establish career pathways. This report aims to: 1) collect relevant overseas and Australian evidence about the employment of people with mental illness; 2) identify the potential benefits of employment; 3) describe patterns of labour force participation in Australia among people with mental illness; 4) identify how mental illness can cause barriers to employment; 5) outline the type of employment restrictions reported by people with mental illness; 6) identify the evidence-based ingredients of employment assistance; 7) identify relevant policy implications; and 8) suggest strategies to improve employment outcomes and career prospects for people with mental illness.
\end{abstract}

\section{Keywords}

mental illness, work, policy development, vocational interventions, supported employment, evidence-based components

Note: Figure 1 on page 10 requires colour printing.

Contact: Geoff Waghorn, Centre for Mental Health Research (QCMHR), School of Population Health, University of Queensland, Australia. geoff_waghorn@qcmhr.uq.edu.au

Citation: Waghorn, G. \& Lloyd, C. (2005). The employment of people with mental illness. Australian e-Journal for the Advancement of Mental Health, 4(2), Supplement. www.auseinet.com/journal/vol4iss2suppl/waghornlloyd.pdf

Published by: Australian Network for Promotion, Prevention and Early Intervention for Mental Health (Auseinet) www.auseinet.com/journal

Received 6 May 2005; Accepted 29 September 2005 


\section{The employment of people with mental illness}

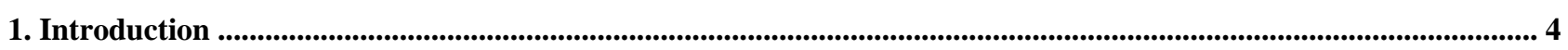

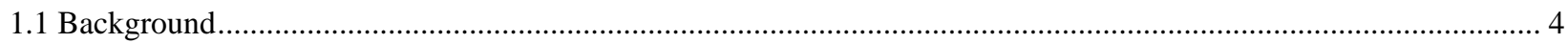

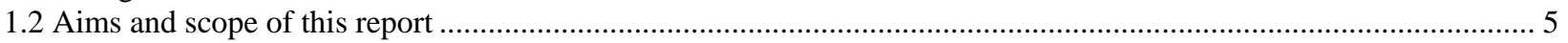

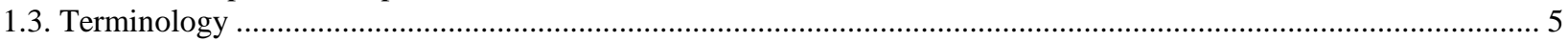

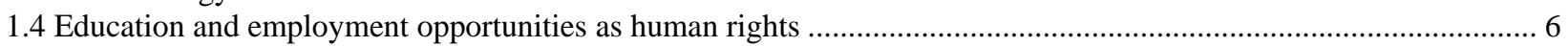

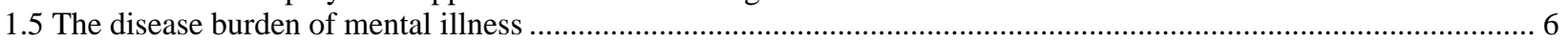

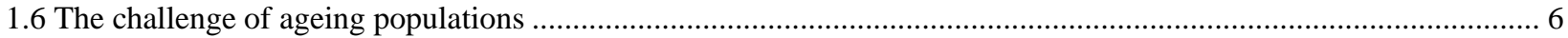

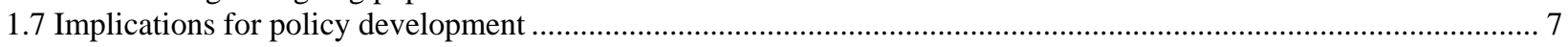

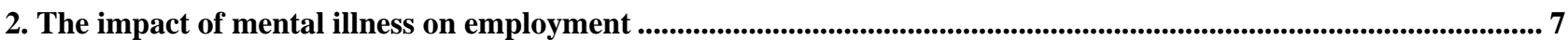

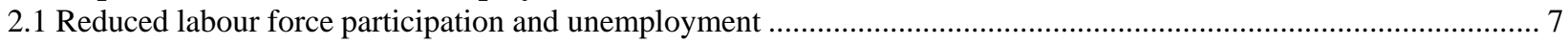

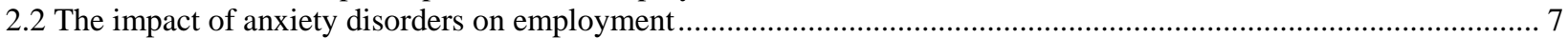

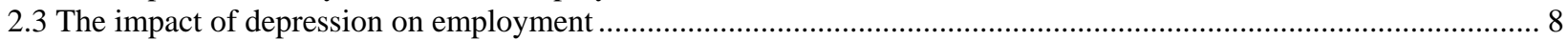

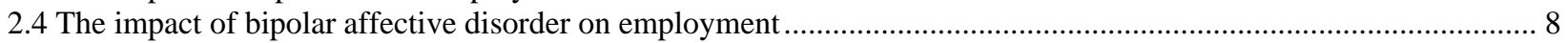

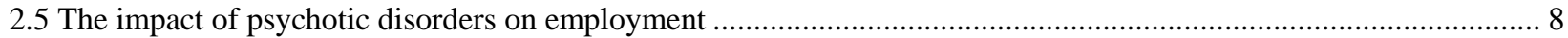

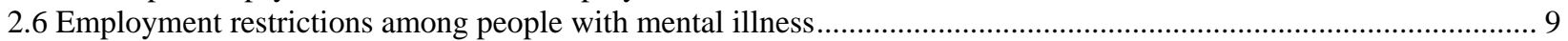

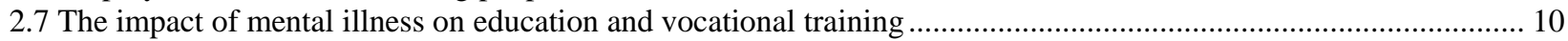

2.8 The need for specialised treatments to reduce employment restrictions .......................................................... 11

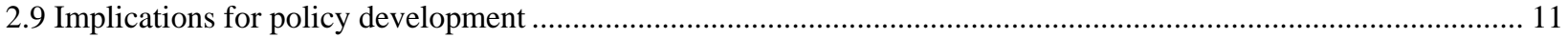

3. Capacity and desire to work

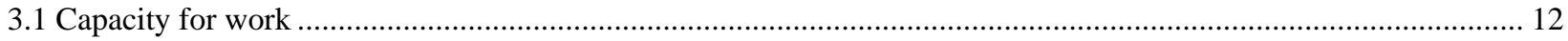

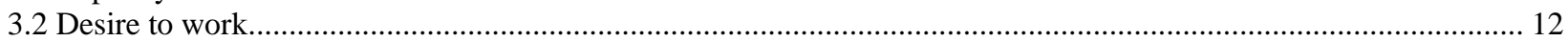

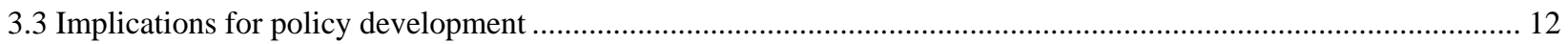

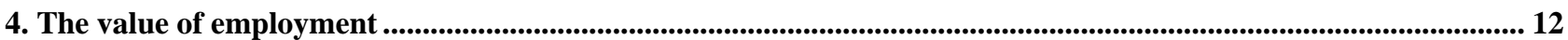

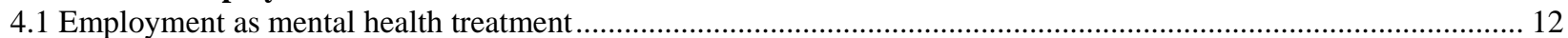

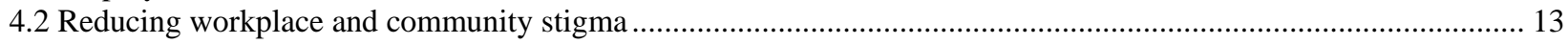

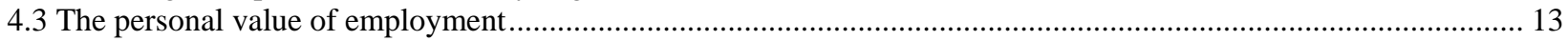

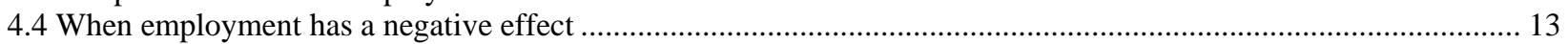

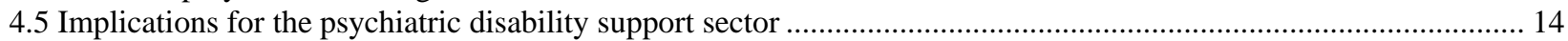

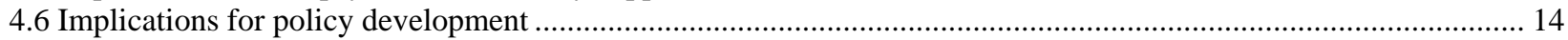

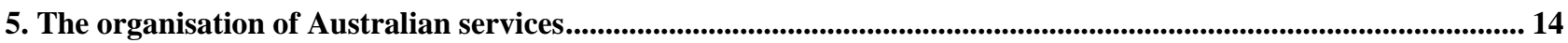

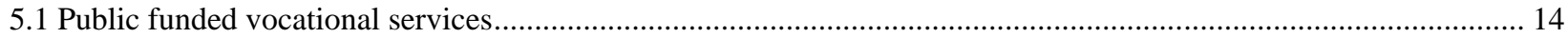

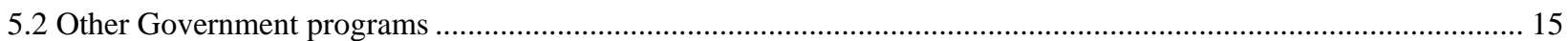

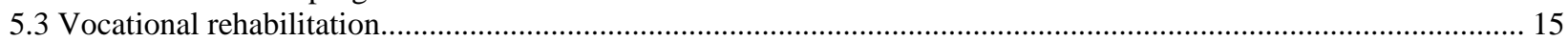

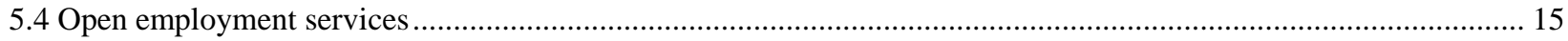

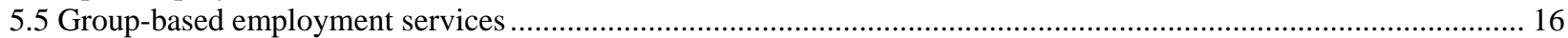

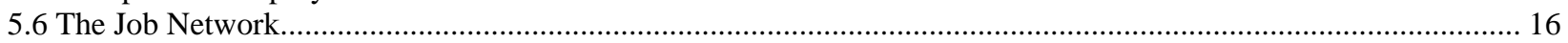

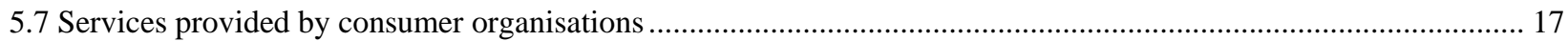

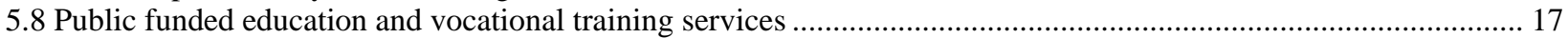

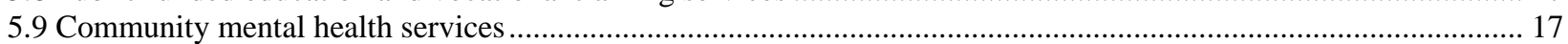

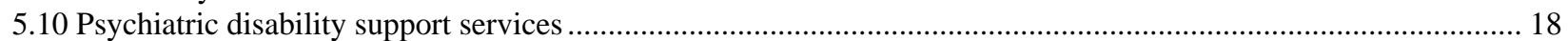

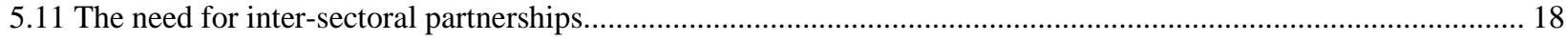

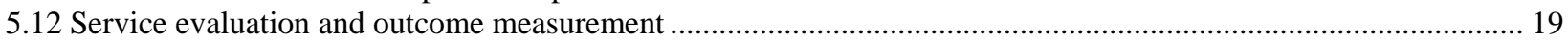

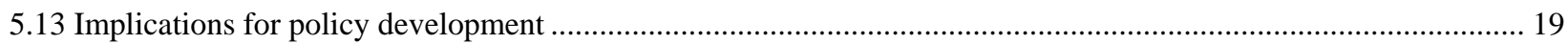




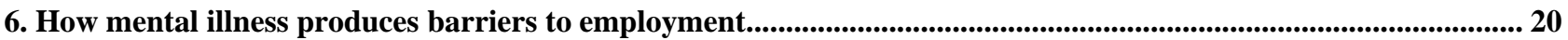

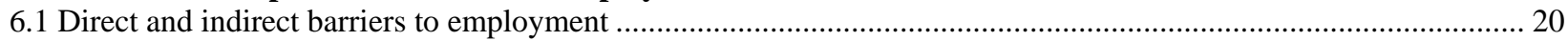

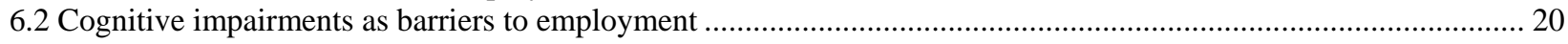

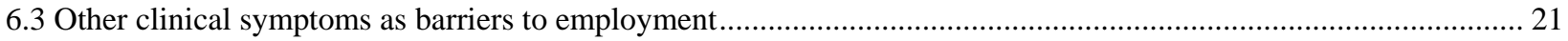

6.4 The episodic nature of the disorders as a barrier to employment...................................................................... 21

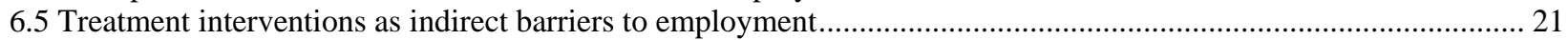

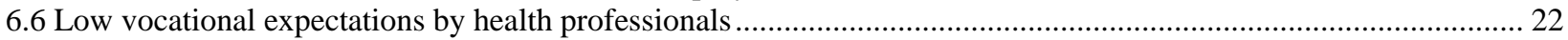

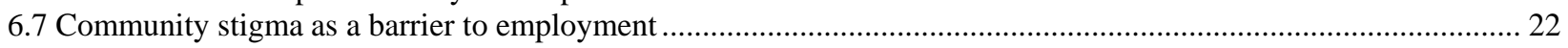

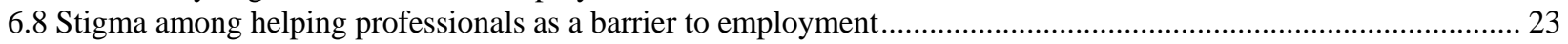

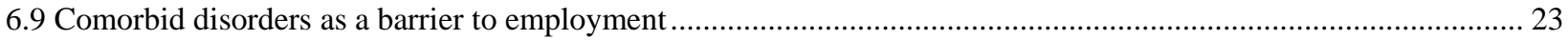

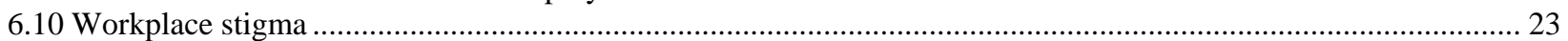

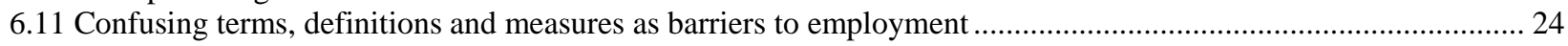

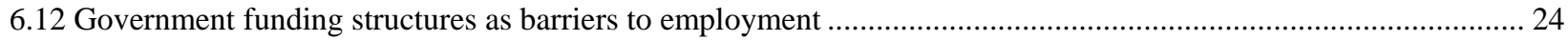

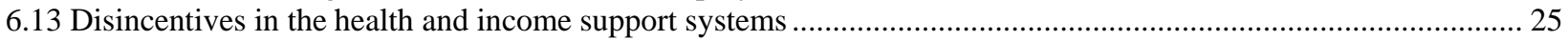

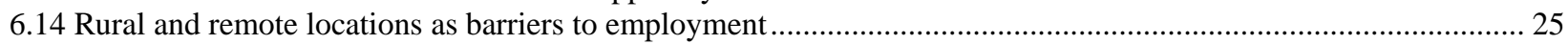

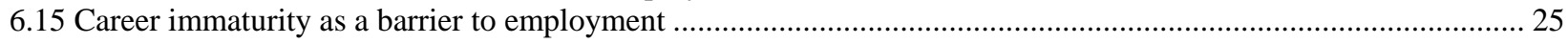

6.16 Subjective experiences and personal resources as barriers to employment .................................................. 25

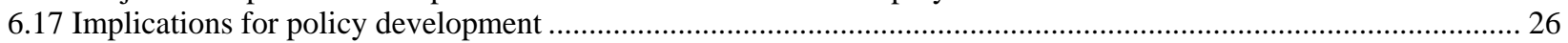

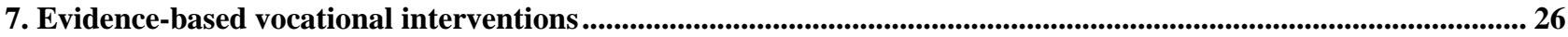

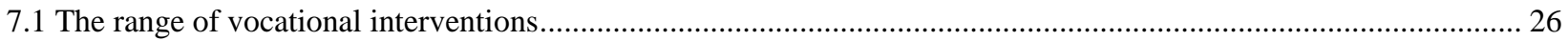

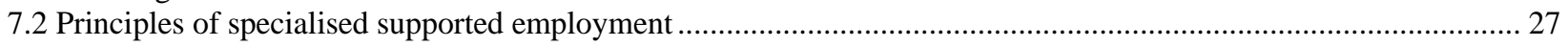

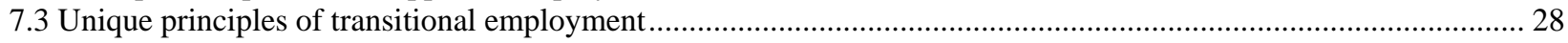

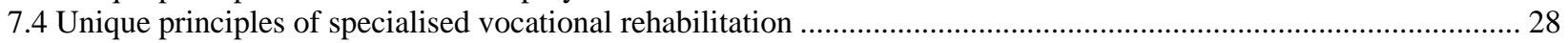

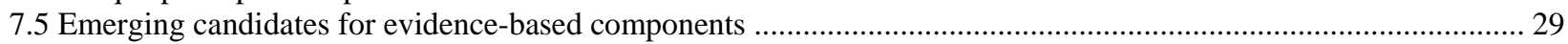

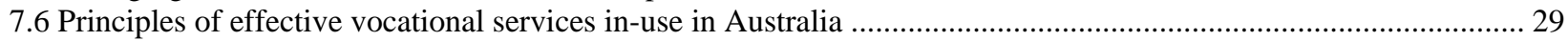

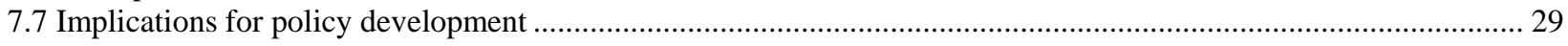

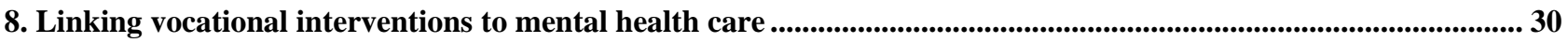

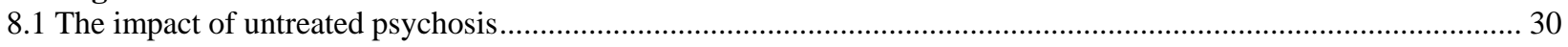

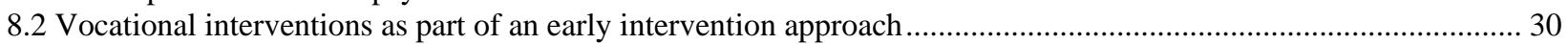

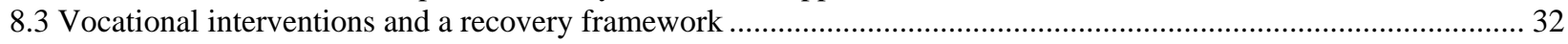

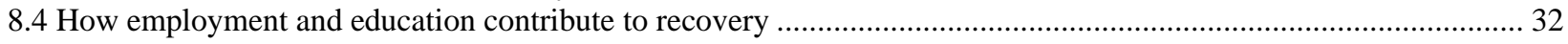

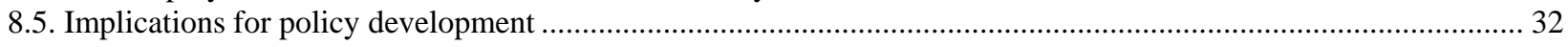

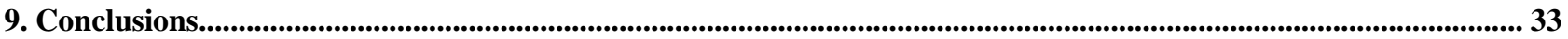

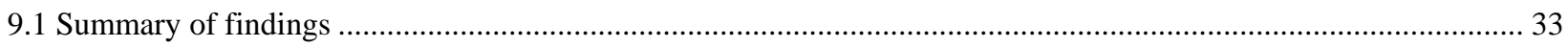

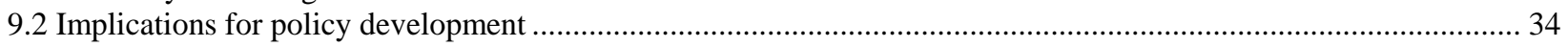

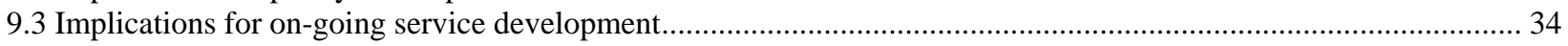

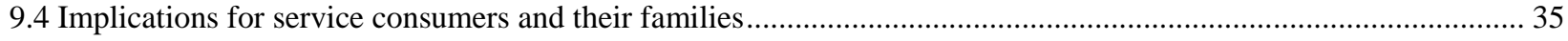

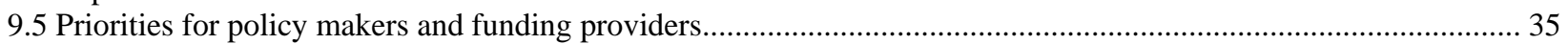

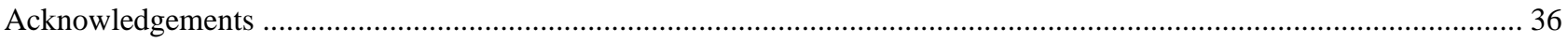

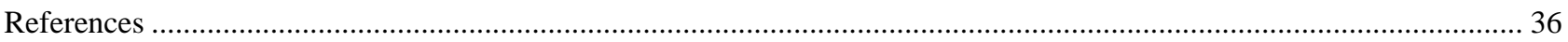




\section{Introduction}

\subsection{Background}

There is substantial evidence that the vocational rehabilitation needs of people with mental illness are not being adequately addressed. High levels of unemployment and non-participation in the labour force prevail among people with mental illness in Australia and in other countries with developed market economies. Labour force non-participation and unemployment levels of $75-90 \%$ are found in the United States [1], 61-73\% in the United Kingdom, and reach 75-78\% among people with psychotic disorders in Australia [2-3]. In a recent Australian survey of 134 disability employment service providers assisting 3025 jobseekers [4], psychiatric or psychological disabilities represented the largest category (30\%) and fared worse than any other disability category in terms of both securing and retaining employment. Following 16 months of disability employment assistance, $44 \%$ of job seekers with psychiatric disabilities remained unemployed, while only $23 \%$ attained durable employment, defined as accumulating 6 months or more of employment of 8 or more hours per week. These statistics indicate that despite the availability of assistance in Australia, the majority of people with mental illness appear excluded from employment opportunities. To counter this disadvantage, more effective assistance appears needed to help people with mental illness establish and re-establish career pathways, to reduce exclusion from mainstream society, and to increase prospects for equitable social and economic participation.

In countries with developed market economies, people with mental illness experience difficulties in achieving the basic right to work [5]. They are also sensitive to the negative effects of unemployment and the loss of purpose, structure, roles, status, and sense of identity which employment provides [6]. Employment enables social inclusion in the wider community and represents an important way people with mental illness can meaningfully participate in society. People with mental illness need the same opportunities to participate in life activities and their local communities as people with good mental health [7].

Australia has a national mental health strategy [8-14] which guides on-going reform of mental health services. This strategy recognises the challenge of inter-sectoral difficulties in terms of disability support, education, housing, and employment. However, the intersectoral collaborations called for by the strategy have not been adequately evaluated [8,11]. This is probably because no such collaborations appear to have materialised, even though these are recognised as essential to address the social and economic marginalisation of people with mental illness [13-14]. More specific strategies appear needed to restore the career disruption caused by mental illness and to restore functioning in socially-valued roles. Such roles in education, employment, parenting and caring for others, are not automatically restored with clinical improvement and may remain impaired throughout the lifespan, even when full remission of clinical symptoms is achieved.

This policy and service delivery failure was recently highlighted by the Queensland Public Advocate who observed that people with mental illness would be better served if public mental health services adopted recovery-oriented practices beyond a strict bio-medical approach. A broader recovery oriented approach was recommended [15, pp. 29-30] which "...integrates peer support, housing, community infrastructure, vocational rehabilitation and training, and other key sectors."

The lack of inter-sectoral collaboration in Australia exacerbates the structural division of public mental health services from other key sectors such as housing and employment. This in turn obstructs intersectoral policy development as well as the coordination and delivery of mental health and vocational services [16]. Mental health expertise and specialised vocational rehabilitation expertise remain insulated within their respective sectors with little knowledge transfer across sectors. Consequently, Australian clinicians may not be aware of developments in the emerging science of psychiatric vocational rehabilitation, and may not understand how employment is feasible even when more severe psychiatric symptoms and disabilities are present. 
Through similar structural isolation from clinicians, vocational professionals can lose touch with the latest developments in mental health treatment. Subsequently, they may not be aware of current treatment goals and methods, may fail to recognise ineffective or sub-optimal treatment, and may miss opportunities for identifying alternative or enhanced treatments likely to reduce employment restrictions, and improve health outcomes as well as employment prospects. In addition, when uncoordinated, both treatment and vocational plans are at risk of mutual interference, which at any time can obstruct progress in both domains and negatively impact on mental health consumers, their families and carers.

\subsection{Aims and scope of this report}

This report aimed to: (1) collect relevant overseas and Australian evidence about the employment of people with a mental illness; (2) identify the potential benefits of employment; (3) describe patterns of labour force participation in Australia among people with mental illness; (4) identify how mental illness can cause barriers to employment; (5) outline the type of employment restrictions reported by people with mental illness; (6) identify the evidence-based ingredients of employment assistance; and (7) identify policy implications and (8) suggest strategies to improve the career prospects of people with mental illness.

\subsection{Terminology}

The term mental illness refers to clinically diagnosed mental disorders such as the anxiety, affective, and psychotic disorders as defined by DSM-IV and ICD-10 classification systems [17-18]. The term mental illness represents more than mental health problems, a term used to refer to short-term adverse mental health states which can occur in response to life stressors and challenging life events. Psychotic disorders typically refer to schizophrenia spectrum disorders, bipolar disorders (when psychosis is present), depression (with psychosis) and other mental disorders involving disturbances of thought and perception.

In the USA, the term supported employment refers to an approach to vocational rehabilitation emphasising 'place and train' in competitive employment opportunities, as opposed to 'train and place' the approach associated with traditional vocational rehabilitation. On-going assessment is conducted in real work contexts, and lengthy pre-employment assessments and gradual stepwise approaches to vocational rehabilitation are avoided whenever possible. In Australia, the nearest equivalent term is open employment as defined in the Australian Government's Disability Services Act, 1986. Similarly defined in this Act, the term supported employment refers to group-based assistance provided by business services, offering sheltered work in modified (not fully competitive) work settings. One or more disability categories may be accommodated by business services (previously known as sheltered workshops) more often for intellectual and physical than for psychiatric disability. In this report the USA meaning of the term supported employment is used.

Whereas work can refer to any structured non-recreational activity, employment is defined by the Australian Bureau of Statistics (ABS) as paid work of one hour or more per week in accordance with industrial awards, unpaid work in a family business, or unpaid work on a family farm. Competitive employment is a widely agreed priority for psychiatric vocational rehabilitation [19-22] and is defined as: part-time or full-time work in the competitive labour market at award wages with supervision provided by personnel regularly employed by the business. The nearest equivalent official term in Australia is open employment. In competitive employment the work is to be performed alongside non-disabled people in integrated settings and the job can be filled by people without disabilities. Although the job design may be modified, it is not designated exclusively for a person with a disability. Competitive employment is distinguished from sheltered work, voluntary work, or pre-vocational training. Sheltered work is characterised by one or more of: additional supervision by mental health staff or by other staff external to the workplace; pay at less than the minimum award wage; use of a supported wage award; segregated work settings; or jobs reserved exclusively for people with disabilities. 
Vocational rehabilitation is another term which can cause confusion. In a general sense it refers to a form of psychosocial rehabilitation where the focus is on restoring (rehabilitating) career pathways, often in conjunction with other forms of psychosocial treatment and rehabilitation. In Australia, the term also refers to the type of vocational assistance typically provided by CRS Australia, as the Government owned sole public provider, where a rehabilitation partnership is developed and intensive efforts can be made to prepare a person for employment, secure employment, and provide support to achieve continuous employment for three months, or until the rehabilitation consultant is confident the position is stable. At its best, the Australian version appears more intensive than the form provided in the U.S.A., where case loads may be higher and less intense assistance appears to be provided.

\subsection{Education and employment opportunities as human rights}

Although Australia does not have a Constitutional Bill of Rights, individual responsibilities and rights are implicit in Australian citizenship. All people in our community have the right to suitable employment in conditions which reflect equity, security, human dignity and respect. Work is important to the mental health and wellbeing of individuals. It is a central aspect of life for most people and provides economic security, valued personal roles, social identity, and an opportunity to make a meaningful contribution to the community. Suitable employment enables social and economic participation in society. Opportunities for social and democratic participation are critical elements to the mental health and wellbeing of individuals, organizations, communities, and nations [23].

According to Australia's National Mental Health Plan 2003-2008 [9, p. 5], Australians, including people with mental illness, have a fundamental right to both education and employment:

The human rights of all people in Australia should be respected. Individuals should not be discriminated against in housing, law, employment, or education. Mental health problems and mental illness should not be stigmatised in the media, by the general community or by mental health services themselves.

Despite a 65\% increase in Government spending on mental health throughout 1993-2002 [8], people with mental illness continue to be socially and economically marginalised from mainstream Australian society. More role-specific assistance appears needed to enable people with mental illness to participate in the socially-valued roles implicit with citizenship, such as worker, student, rehabilitation participant, carer, or homemaker. These roles enable people with mental illness to outgrow the roles of mental health patient and welfare recipient, which attract additional stigma and unfair discrimination.

\subsection{The disease burden of mental illness}

Mental illnesses are the third leading cause of overall disease burden in Australia (14\% of total) following cardiovascular diseases $(20 \%)$ and cancers $(19 \%)$, as measured by disability adjusted life years, a scale of disease burden combining the influences of mortality and morbidity. In terms of morbidity, as measured by life years lost to disability, mental illnesses are the leading cause of disease burden in Australia [24]. Participation in employment and other socially-valued roles can reduce the high burden of mental illness by reducing the secondary effects of social and economic marginalisation on individuals. Employment may also reduce the burden on families and carers, although to date there is no evidence to support this expectation. The financial burden on the community may also reduce with greater participation in employment and other socially-valued roles, through reduced welfare dependence, reduced use of public mental health services, and greater involvement in local communities.

\subsection{The challenge of ageing populations}

Reducing the impact of mental illness on labour force participation and employment can contribute to meeting the challenge of ageing populations. The Organisation for Economic Co-operation and Development (OECD) advise member countries [25-27] to implement policies reducing the dependence ratio of older people (aged 65 years or older) to those of working age (15-64 years). The OECD warns that failure to heed this advice will lead to falling living standards as the dependence ratio increases from $22 \%$ 
to $46 \%$ by the year 2050 . To help achieve this, the impact of mental disorders on labour force participation and career pathways needs to be reduced. This may require a coordinated Government approach via health treatment services, income support and taxation systems, as well as through improved Job Network, disability employment services, and vocational rehabilitation services.

People with mental illness over 55 years of age face additional disadvantage as members of the ageing community. Through reduced employment opportunities throughout the working life they may be more poverty prone in retirement and may have left the workforce years earlier than people without mental illness (see Figure 1). For those continuing employment or voluntary work in the community, additional barriers can emerge with ageing, such as transport problems, the onset of age-related physical limitations and disabilities, difficulty accessing health and mental health services, and difficulty accessing vocational service providers willing to provide appropriate assistance. The combination of mental illness and ageing highlights the need for disability and lifestyle support for people with mental illness throughout the life span, independently of role specific assistance in education or employment.

\subsection{Implications for policy development}

Equitable access to career opportunities throughout the working life is an implicit right of Australian citizenship which are not restored by the provision of mental health services alone. Governments have a social justice obligation to prevent mental illness becoming a life-sentence of social and economic marginalisation. Evidence-based forms of disability-specific education and employment assistance appear needed to address the lifelong social and economic marginalisation caused by mental illness. Employment and education assistance are not intended to displace disability and independent living support provided by the psychiatric disability services sector. National strategies to combat the challenge of ageing populations can include specific strategies to encourage labour force participation by people with mental illness throughout the working life. Additional disability support strategies will be needed to accommodate the increasing assistance needs of ageing people with mental illness.

\section{The impact of mental illness on employment}

\subsection{Reduced labour force participation and unemployment}

Recent Australian population surveys provide evidence of career disadvantage among people with mental illness. For example, from the Australian Bureau of Statistics (ABS) Survey of Disability, Ageing and Carers, 1998 [3,28-31] found that 75\% of people with psychotic disorders and $47.1 \%$ of people with anxiety disorders did not participate in the labour force. These levels represent 3.8 times, and 2.4 times respectively, the $19.9 \%$ non-participation by healthy Australians aged 15-64 years.

\subsection{The impact of anxiety disorders on employment}

Anxiety and depression are prevalent in the community and together are found in approximately $5-10 \%$ of the population [32-36] at any time. Although anxiety disorders are among the most treatable mental disorders, in a recent national survey [26] $40.9 \%$ of people with anxiety disorders reported not receiving mental health treatment. Of those that receive treatment, not all received optimal treatment [37,38]. Anxiety disorders are associated with increased non-participation in the labour force, deflated employment trajectories (see Figure 1) and impaired work performance compared to healthy people [30,31,39]. People with anxiety disorders are also unlikely to receive appropriately intense employment assistance, because in the ABS survey mentioned, only $2.5 \%$ of persons with anxiety disorders reported receiving job placement assistance [31].

People with more severe forms of anxiety disorders such as obsessive compulsive disorder (OCD), panic disorder (PD), generalised anxiety disorder (GAD), and posttraumatic stress disorder (PTSD), may be particularly disadvantaged. These anxiety disorders commonly produce severe to profound employment restrictions. Treatment of these disorders can require specialised therapies (e.g. cognitive behaviour therapy, graduated exposure therapies, narrative therapy, motivational interviewing) in addition to usual 
psychiatric treatment [38]. However, the limited public funding and partial medical insurance coverage for specialised psychological treatments in Australia, means that these treatments may be too expensive for most people.

\subsection{The impact of depression on employment}

Depression, like anxiety, often remains untreated, and not all people treated for depression receive optimal treatment. In the SDAC 1998 [29], 56\% of people with clinical depression received any form of professional treatment. Depression is known to cause absenteeism from work [39-42] and impair work performance when at work [40, 43-45]. People with depression also have reduced labour force participation, reduced working hours and may earn less than healthy workers [46]. In U.S.A. studies, more sick days were found lost from depression than any other health condition [41-42]. Furthermore, depression is associated with five times more work days impaired through presenteeism (present at work but not functioning as efficiently) than lost to absenteeism [39,44].

People with depression may have impaired motivation, impaired decision making, and a reduced capacity to initiate a particular course of action. Depression can be misunderstood by employers and vocational service providers as poor motivation for work generally, or when employed, as low motivation for working productively. Like those with psychotic disorders or severe anxiety disorders, people with dysthymia and major depression may need specialised treatment to reduce employment restrictions, and may need a relatively intensive and continuous form of vocational rehabilitation to help restore and maintain career pathways.

\subsection{The impact of bipolar affective disorder on employment}

Little is known about the impact of bipolar affective disorder on employment. In a recent national mental health survey [47] 61.8\% of those with a diagnosis of bipolar affective disorder were not participating in the labour force, $4.5 \%$ were looking for work, and $28 \%$ were employed. The effect of this disorder on employment approaches the magnitude of the effect caused by psychotic disorders. However, anecdotal evidence indicates that this disorder can fluctuate more than most other mental disorders, and may involve a manic phase where productivity and creativity can be high, where time and energy management may be impaired and the person may over-exert themselves until a depression cycle is reached. The danger with this disorder is that a continuing need for assistance may not be recognised due to apparent high functioning during the well or early manic phases. In addition, the person affected by this disorder may correctly judge that assistance is not needed during the manic phase, but may forget the extent of difficulty experienced during the depressive phase. People with bipolar affective disorders may have relatively little difficulty obtaining employment, but unless new strategies are learned to monitor warning signs (e.g. increasing energy, productivity and creativity at work; or increasing social withdrawal at work and difficulty getting to work) job retention is likely to be the major issue. Treatment plans coordinated with vocational plans and interventions, with access to continuing support as needed, can be essential to achieve sustainable employment for people with this disorder.

\subsection{The impact of psychotic disorders on employment}

The onset of psychotic disorders can permanently disrupt education, employment and career development [2,3]. Although of low point prevalence compared to anxiety and depression at approximately $0.47 \%$ of the population [47], psychotic disorders are associated with lifelong career disruption. In 1998 [3] 75.2\% of householders with psychosis were non-participants in the labour force, $21.1 \%$ were employed, and $3.7 \%$ were looking for work (see Table 2). Despite evidence of career disruption, long-term outcome studies [48] and successful vocational programs [19-22,49-50] support the feasibility of employment for a substantial proportion of persons with psychotic disorders. 
Table 1. Labour force activity among Australians with anxiety disorders aged 15-64 years compared to persons without disability or long-term health conditions.

\begin{tabular}{|c|c|c|c|}
\hline & $\begin{array}{r}\text { Not in the labour } \\
\text { force } \\
\%^{\mathrm{a}}\end{array}$ & $\begin{array}{r}\text { Looking for work } \\
\%^{a}\end{array}$ & $\begin{array}{r}\text { Employed part time } \\
\text { or full time } \\
\%^{\mathrm{a}}\end{array}$ \\
\hline \multicolumn{4}{|l|}{$\begin{array}{l}\text { Persons with ICD-10 anxiety disorders and } \\
\text { employment restrictions of which the most } \\
\text { restrictive is: }\end{array}$} \\
\hline profound & ** 100.0 & **0.0 & **0.0 \\
\hline severe & $* * 60.1$ & ${ }^{c *} 5.5$ & $b^{* *} 34.3$ \\
\hline moderate & ${ }^{\mathrm{ns}} 32.7$ & ns 12.9 & **54.3 \\
\hline mild & *45.3 & $\star * 6.1$ & **48.6 \\
\hline no employment restrictions ${ }^{d}$ & 23.2 & 9.2 & 67.6 \\
\hline Total persons with ICD-10 anxiety disorders & 47.1 & 7.5 & 45.4 \\
\hline $\begin{array}{l}\text { Persons without disability or long-term } \\
\text { health conditions (Controls) }\end{array}$ & 19.9 & 6.3 & 73.8 \\
\hline
\end{tabular}

Notes: a. Row percentages shown. b Standard errors represent 25-50\% of the estimate value. c. Standard errors exceed $50 \%$ of the estimate value. d. Reference level. ${ }^{* *}$ Statistically significant at the $99.9 \%$ confidence level for $Z$ score of difference with respect to within column reference level. * Statistically significant at the $95 \%$ confidence level. ns Not significantly different from the reference level of no employment restrictions.

\subsection{Employment restrictions among people with mental illness}

At a population level [30] the most commonly reported employment restrictions among people with anxiety disorders are: restricted in the type of job (24.0\%); need for a support person (23.3\%); difficulty changing jobs (18.6\%); and restricted in the number of hours (15.4\%). A substantial proportion of people with anxiety disorders $(23.3 \%)$, and $61.3 \%$ of people with psychotic disorders [3], report a need for a support person if participating in employment (see Table 3). The high proportions of people with anxiety disorders reporting employment restrictions (from Table 1: severe to profound 26.7\%; mild to moderate, $36.9 \%$; no employment restrictions $36.5 \%$ ) indicate a need for services which can both reduce employment restrictions and help employers to accommodate these restrictions in the workplace.

The psychotic disorders are associated with the greatest proportions of employment restrictions. However, substantial proportions of people with depression and anxiety disorders also report employment restrictions [30]. Figure 1 shows how the impact of depression and anxiety disorders on employment, also depends on age and the severity of employment restrictions [51].

Table 2. Labour force activity by employment restrictions among Australian householders with psychotic disorders aged 15-64 years.

\begin{tabular}{|c|c|c|c|c|}
\hline & $\begin{array}{r}\text { Not in the } \\
\text { labour force } \\
\%^{\mathrm{a}}\end{array}$ & $\begin{array}{r}\text { Looking } \\
\text { for work } \\
\%^{\mathrm{a}}\end{array}$ & $\begin{array}{r}\text { Employed part } \\
\text { time or full-time } \\
\%^{\mathrm{a}}\end{array}$ & $\begin{array}{r}\text { Persons } \\
\%^{\mathrm{a}}\end{array}$ \\
\hline \multicolumn{5}{|l|}{$\begin{array}{l}\text { Persons with psychosis and employment restrictions, of } \\
\text { which the most restrictive are: }\end{array}$} \\
\hline $\begin{array}{l}\text { profound } \\
\text { severe }\end{array}$ & $\begin{array}{l}100.0 \\
{ }^{b} 88.2\end{array}$ & $\begin{array}{l}0.00 \\
0.00\end{array}$ & $\begin{array}{r}0.0 \\
{ }^{c} 11.8\end{array}$ & $\begin{array}{r}100.0 \\
b_{1} 100.0\end{array}$ \\
\hline moderate & ${ }^{c} 32.6$ & 0.00 & ${ }^{\mathrm{b}} 67.4$ & ${ }^{b} 100.0$ \\
\hline mild or none & ${ }^{\mathrm{c}} 77.2$ & 0.00 & ${ }^{c} 22.8$ & ${ }^{c} 100.0$ \\
\hline $\begin{array}{l}\text { Persons with psychosis, without activity or employment } \\
\text { restrictions }\end{array}$ & ${ }^{\mathrm{b}} 50.0$ & ${ }^{\mathrm{c}} 14.7$ & ${ }^{\mathrm{b}} 35.3$ & ${ }^{b} 100.0$ \\
\hline households & 75.2 & ${ }^{c} 3.7$ & 21.1 & 100.0 \\
\hline $\begin{array}{l}\text { Control group. Healthy persons aged } 15-64 \text { years, } \\
\text { without disability or long-term health conditions. }\end{array}$ & 19.9 & 6.3 & 73.8 & 100.0 \\
\hline
\end{tabular}

Notes: a. Percentages shown sum to 100 within rows. b. Standard errors represent 25-50\% of the estimate value. c. Standard errors exceed $50 \%$ of the estimate value. 
Table 3. Employment restrictions among Australians aged 15-64 years with anxiety disorders compared to those with psychotic disorders.

\begin{tabular}{lrr}
\hline Type of employment restriction $^{\text {a }}$ & $\begin{array}{r}\text { Persons with anxiety } \\
\text { disorders } \\
\%^{\mathbf{b}}\end{array}$ & $\begin{array}{r}\text { Persons with psychotic } \\
\text { disorders } \\
\%^{\mathbf{b}}\end{array}$ \\
\hline Need for a support person & 23.3 & 61.3 \\
Restricted in type of job & 24.0 & $* 31.2$ \\
Difficulty changing jobs or getting a better job & 18.6 & $* 28.3$ \\
Restricted in number of hours & 15.4 & $* 18.1$ \\
Need for ongoing supervision or assistance & 3.2 & $* 12.7$ \\
Need for time off work & 7.7 & $* 12.5$ \\
Need for special arrangements or equipment & 5.5 & $* * 1.0$ \\
No employment restrictions & 12.5 & $* * 6.9$ \\
Total persons aged 15-64 years & 100.0 & 100.0 \\
\hline
\end{tabular}

Notes: a. Rows are not mutually exclusive as multiple employment restrictions were frequently reported. $\quad$ b. Column percentages shown. * Standard errors for these estimates represent $25-50 \%$ of the estimate value. ${ }^{*}$ Standard errors for these estimates exceed $50 \%$ of the estimate value.

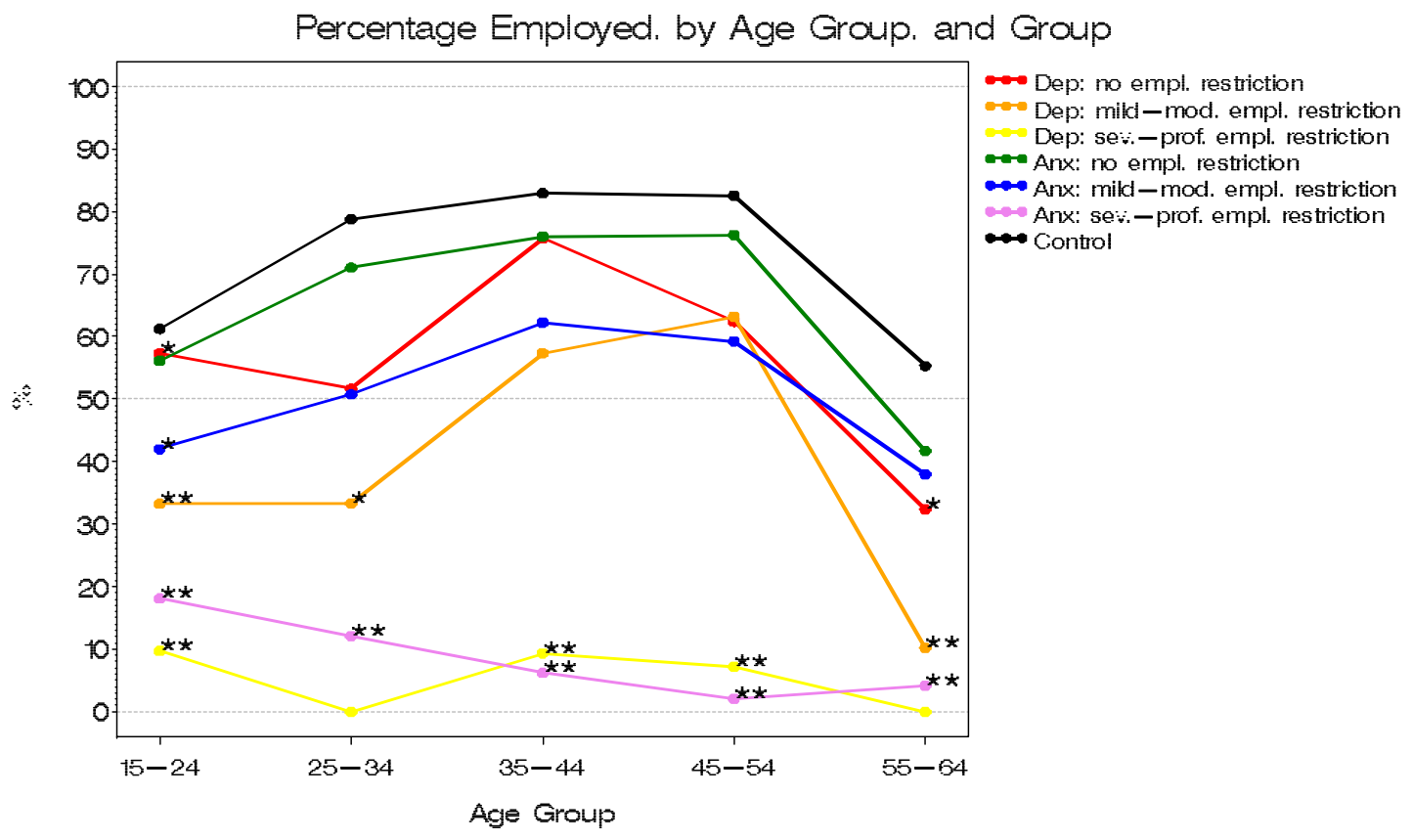

Figure 1. Proportions employed by employment restrictions, diagnostic category and age group, among Australian household residents aged 15-64 years in 1998.

\subsection{The impact of mental illness on education and vocational training}

The onset of mental illness can truncate primary, secondary or tertiary educational attainment and vocational training, and disrupt normal career development. For psychotic disorders, this may occur because the typical onset age is from 10-30 years, which may coincide with the critical career stages of completing formal education and establishing a career pathway. Through disrupting education, mental illness can indirectly cause long-term unemployment and limit career prospects. Hence, mental illness can displace career paths downwards and limit attainment to less skilled jobs, lowering both work status and income expectations. 
Several studies have identified the importance of education to career development. A recent longitudinal study [52] and a secondary analysis of data from the USA National Health Interview Survey on Disability, 1994-95 [53], linked educational attainment to increased employment outcomes and higher employment status in the U.S.A. In Australia, educational attainment is closely associated with employment outcomes. Two national surveys $[2,47,54]$ found positive links between educational attainment and both current employment and durable employment among people with psychotic disorders. Among those not completing secondary school, $11.6 \%$ of people with psychotic disorders reported current employment. The employed proportion increased with secondary school completion $(22.1 \%)$, vocational qualifications (34.3\%), and attaining Bachelor degrees or higher (46.7\%).

The need to restore educational attainment following disruption by mental illness is recognised by the National Mental Health Plan 2003-2008 [9, p. 22]. Federal and State Ministers previously endorsed the findings of the 1995 Mental Health Forum on Intersectoral Linkages supporting linking mental health services with other sectors as a priority under both the first and second plans in 1992 and 1997. However, this need was overlooked by Australian welfare and disability employment service reform throughout the 1990s [55]. In the current mental health plan, the key directions (18.1-18.3) refer to fostering non-specific linkages between sectors and levels of Government at a local level. However, evaluations of the plan to date have not reported on progress with respect to establishing inter-sectoral links [8].

\subsection{The need for specialised treatments to reduce employment restrictions}

The public mental health sector in Australia represents an alternative source for specialised psychological and psychiatric treatment for all forms of mental disorders, which can target and ameliorate employment restrictions. However, service priorities and admission criteria vary by State and Territory. In some States, people with severe anxiety disorders can be excluded from the public mental health system because of high demand for services and because psychotic disorders may be considered a higher priority. In other States, people with more severe anxiety disorders can obtain access to good psychiatric care, case management, and specialised therapies. That this is not uniform across Australia is unfortunate because public mental health services have the multidisciplinary teams capable of being trained in providing the full range of specialised treatments required for these disorders.

In some states and territories, people with mental disorders can have difficulty obtaining both optimal treatment and suitable vocational assistance. They may be turned away by vocational professionals who recognise the extensive employment restrictions associated with the severe forms of these disorders. Vocational professionals may be unwilling or unable to provide specialist psychological and psychiatric treatments as part of a comprehensive vocational rehabilitation plan. However, specialised psychological treatments coordinated by a vocational plan may be particularly effective through leveraging treatment motivation with vocational motivation. Providing timely and effective supplementary treatment is therefore likely to reduce employment restrictions and increase the prospect of favourable vocational outcomes. Specialised treatment need not delay vocational plans because these can be provided in parallel with vocational interventions.

\subsection{Implications for policy development}

Lower levels of employment restrictions among people with mental illness are associated with greater labour force participation and employment participation. Those with more severe employment restrictions who have lower educational attainment are the most disadvantaged.

At a population level the evidence indicates that more can be done to assist Australians with a mental illness to participate in formal study, vocational training and employment. It is likely that people with mental illness could benefit from more assistance to access suitable services, and may benefit from more intensive, continuous and individually tailored assistance than is currently provided.

Specific strategies are needed to allocate responsibilities for the funding and delivery of disability-specific education assistance in primary, secondary, vocational, and higher education, over and above the generic assistance available to people with all categories of disability at education institutions. 


\section{Capacity and desire to work}

\subsection{Capacity for work}

Non-participation in the labour force and high unemployment do not mean that people with mental illness are incapable of working. Studies of the long-term course of illness and health outcomes of people with schizophrenia [53,56-61] have found substantial heterogeneity of course and outcome, with improvement over time in social functioning in $40-70 \%$ of people previously classified as having the most severe disabilities.

Controlled studies of the effectiveness of supported employment [20] demonstrate the feasibility of competitive employment, even when no screening criteria other than initial interest, determine program entry. In a recent review, Bond found that $40-60 \%$ of consumers receiving evidence-based supported employment assistance obtained competitive employment. Long-term outcome research and controlled studies of supported employment support the feasibility of psychiatric vocational rehabilitation for people with mental illness, including a substantial proportion of persons with the most severe forms of schizophrenia.

\subsection{Desire to work}

Labour force non-participation and high unemployment do not imply that people with mental illness do not want to work. Low labour force participation may represent discouraged job-seeking or loss of vocational-hope, because a substantial proportion of mental health service consumers with severe mental illness consider employment feasible [62] and a key element to their recovery [63-65]. When specifically prompted, consumers frequently state that they want employment [57,66-68] even when mental health providers rate employment as a low priority [69]. Other qualitative studies [70-75] have found that people with a severe mental illness actively strive to obtain meaningful roles and an appropriate vocational place in the community.

Not every person with a mental illness regards competitive employment a feasible goal, or regards the return to expected roles as necessary for their recovery [62]. For some people, alternative socially-valued roles as students, rehabilitation participants, voluntary workers, partners, homemakers, parents, and carers, can be equally important depending on personal circumstances and the extent each alternative role offers meaning and purpose to life [75], while reducing the stigma associated with roles of low or negative social value [76-77].

\subsection{Implications for policy development}

A substantial proportion of people with mental illness have the capacity and desire to work but may not be aware of available assistance or may have lost hope of gaining a vocational place in the community. Improved pathways to assistance, and more evidence-based forms of assistance, appear necessary to reestablish career pathways following the onset of a mental illness. The implication for policy makers is that there is a need to educate the community about the feasibility of employment by people with mental illness, and to ensure that suitably intense, evidence-based, and more continuous forms of assistance are provided. In addition, support is needed for socially-valued roles other than employment, which can also help people regain a valued place in society.

\section{The value of employment}

\subsection{Employment as mental health treatment}

Extensive claims have been made for the value of work in psychiatry. From these, Rowland and Perkins [68] identified four benefits of work: work as a restorative psychological process; work to improve selfconcept; the protective effect of work; and the social dimension of work. Although there is limited Australian evidence, in North America the evidence suggests that for those seeking employment assistance, employment has few negative effects and is more beneficial than voluntary work [20]. 
Positive and meaningful employment experiences have been linked to improved self-concept and selfefficacy [75], higher ratings of subjective well-being [78], regaining self-esteem [79], improved engagement in work activity with associated symptom reduction [80-81] and increased personal empowerment [82]. Work may also improve clinical insight for those with severe mental illness who have less severe cognitive impairments [83]. In Australia, participation in vocational rehabilitation provided by CRS Australia is associated with reduced clinical symptoms and higher levels of functioning as measured by the Behaviour and Symptom Identification Scale [84].

\title{
4.2 Reducing workplace and community stigma
}

People with psychiatric disabilities experience considerable stigma and discrimination [76,85-86] from both employers and the general community. Vocational professionals can counter the stigma associated with psychiatric disability by strategic disclosure to employers and to other third parties throughout vocational rehabilitation. Vocational professionals have the opportunity to counter community stigma by enabling people with mental illness to demonstrate their work potential. Personal contact with people experiencing mental illness in the workplace, supported by planned education of managers, supervisors and co-workers, may counter stigma both in the workplace and in the wider community.

\subsection{The personal value of employment}

Reviews of randomised controlled trials [20] reveal that the main benefit of supported employment is on short-term individual employment outcomes. Other benefits associated with work include structuring time and routine, social contact, collective effort and purpose, social identity and status, personal achievement, and regular activity and involvement [5-6].

However, job retention challenges all forms of employment assistance [87-88] indicating that continuing support to retain employment is critical for people with mental illness. Although there is evidence that sustained employment enhances the non-vocational outcomes of improved self-esteem and symptom control, there is no consistent evidence that employment leads to reduced hospitalisations or improves quality of life [89-90]. Despite these evidence gaps, suitable and meaningful employment can be highly valued by individuals. The following account (Scott, personal communication to MIFA, March 2005) illustrates the personal value of employment:

\begin{abstract}
I have found that working part-time has definitely given me the positive edge on a more healthy self-esteem. Working has taken away the dread of socialising and meeting new people as to when I am asked in conversation, what I do for a living. Once upon a time I had the embarrassment of saying nothing or else saying that I was on a disability pension. Then there was the fear that they would inquire more deeply and I would be exposed as explaining I had a mental illness. With a large portion of society ignorant about mental illness and still having stigma, this position would further squash an already low self-esteem. Working has given me the opportunity to flee this scenario as well as giving me structure and routine.

If I have days or weeks where I'm starting to get slightly unwell, work is the best therapy for me. It gets my eyes off myself and focussed on to others' needs. Being employed as a supervisor of an Activity Drop-In centre for people with a mental illness, I find serving others needs and healing is good for the soul. I have discovered that the best way to help yourself is simply by helping someone else. With mental health issues, loneliness and boredom are a good recipe for becoming unwell and work has structured my time, so even if I feel lazy and unmotivated, I have to get into action and attend and perform in my job. For people who are ready to take the next step of some degree of work I encourage the system to give them every opportunity as it is vital to that road to recovery.
\end{abstract}

\subsection{When employment has a negative effect}

Not every person with more severe forms of mental illness such as schizophrenia who attempts employment, experiences reduced clinical symptoms. For those with severe cognitive deficits, vocational rehabilitation may have negative consequences. By re-examining data from a previous study, Lysaker et al. [83] found a subgroup of people with cognitive deficits whose symptoms either increased or remained the same following five months of vocational rehabilitation. Although the reasons were not established, 
Lysaker et al. suggested that severe cognitive impairments may interfere with the ability to fully appreciate the purpose of a work activity, thereby rendering work activity unduly stressful for some people. For those with severe cognitive impairments who are not interested in competitive employment, alternative forms of meaningful employment may be feasible, or support for alternative socially-valued roles may be indicated.

\subsection{Implications for the psychiatric disability support sector}

Providing more specialised, intensive and continuous support for education and employment should not be at the expense of services in the disability support sector which provide independent living, lifestyle and general disability support to people with mental illness, their families and carers. A distinction can be made between (1) assistance for independent living, social-recreation, non-vocational socially-valued roles; and (2) assistance for the vocational roles of formal study, training and employment. Increasing the value of employment for people with mental illness does not imply displacement of other forms of disability and independent living support. However, change will be needed if existing disability support services are unwittingly discouraging competitive employment, or are providing pre-vocational training as a form of psychosocial rehabilitation, without enabling the realisation of competitive employment goals. Section 7 of this report explains how vocational services are best provided, based on evidence of effectiveness.

\subsection{Implications for policy development}

This evidence indicates that competitive employment opportunities are valued by people with mental illness. However, at any time a proportion of people may need alternatives to competitive employment, or help in transitional steps towards competitive employment that provide opportunities for personal growth and to learn core work skills. Others may have personal circumstances which require their participation in alternative socially-valued and meaningful roles. Those adversely affected by prior stigma experiences may have long-term competitive employment goals yet in the short term may need the benefit of a stigmasafe work environment. The implication for policy development is that while appropriate assistance with formal education and competitive employment is a priority, assistance is also needed with: alternative roles (e.g. as carer, parent, home maker, rehabilitation participant, and student); other personal recovery goals; and with alternative or transitional employment goals. Transitional employment experiences can be used to develop core work skills including work-related social skills, provide vocational training, and facilitate the transition to competitive employment. In this regard, business service forms of employment and Clubhouse transitional employment can play an active part. Social firms and other business services that offer long-term employment can help by providing jobs and career learning experiences in low-stigma work environments.

\section{The organisation of Australian services}

\subsection{Public funded vocational services}

Vocational rehabilitation for physical and sensory disabilities in Australia was established in response to the needs of returning World War II veterans. Open employment services were introduced with the Disability Services Act, 1986. Coverage by disability employment services and vocational rehabilitation was extended to people with mental illness and psychiatric disabilities in the early 1990s.

Australian Government departments were reorganised in 2004 to shift responsibility for open employment services and CRS Australia, from the Department of Family and Community Services (FaCS) to the Department of Employment and Workplace Relations (DEWR). Three types of mainstream services are currently available throughout Australia [16] and are in theory accessible by people with mental illness of working age. These are: (1) disability employment services, including open employment services and business services (group based programs providing employment opportunities in sheltered settings); (2) vocational rehabilitation services (via CRS Australia); and (3) Job Network services. Approximately 10\% 
of open employment services and three CRS Australia outlets specialise in assisting people with mental illness. Applicants are assessed by Centrelink disability officers (the Australian Government's income support agency) and referred to one of the three streams according to the assessed level of employment support needs.

\subsection{Other Government programs}

People with mental illness can access a range of mainstream programs designed to help people when looking for work. These include: Australian Job Search, a job vacancy data base; self-help job search facilities; career information and career planning assistance; Community Development Employment projects for unpaid work and skills development; work for the dole; new apprenticeship access program; self-employment development and new enterprise assistance; and a transition to work program for those who have been out of the workforce for more than two years.

Another Australian Government program titled Australians Working Together offers support services relevant to people with mental illness. These services include: the Personal Support Program (PSP); Voluntary work and community work; Working credits; and Personal Advisors. Further information about these programs and services is available through the FaCS and Centrelink official websites.

Few if any employment services are funded by State Governments in Australia. This is because under the State-Federal Disability Agreement, employment for people with disabilities is an Australian Government responsibility. However, State Governments administer vocational training, which encompasses the new apprenticeship training scheme. This program subsidises training in a range of industry-specific and jobspecific skills. People with mental illness can benefit from the new apprenticeship scheme, which provides access to relevant paid work experience and structured industry-based training.

\subsection{Vocational rehabilitation}

Public funded vocational rehabilitation is available in Australia through CRS Australia (previously the Commonwealth Rehabilitation Service). There are no other authorised providers. However, services from the private rehabilitation sector are routinely contracted by CRS Australia staff. The differences between vocational rehabilitation and open employment services are shown in Table 4. The method of access via Centrelink assessment is the same as for open employment except CRS Australia staff can exclude people from assistance if they consider substantial gain as stated in the Disability Services Act, 1986, is unlikely to be achieved. The additional programs available to open employment services are also available to CRS Australia. The major limitation of vocational rehabilitation provided by CRS Australia is that on-going support is only officially provided for 12-13 weeks, designed to achieve initial stability of the job placement. Anecdotal reports by people with mental illness indicate that CRS Australia services can be effective when the service is accessible. In some cases continuing support can be arranged by transferring the person to an open employment service.

\subsection{Open employment services}

Open employment services are typically non-government organisations, which are soon to be funded on a $100 \%$ per capita basis. People with disabilities are helped to obtain employment in competitive jobs of their choice. Open employment services specialising in psychiatric disability provide five of the seven components (see rows 1-7 of Table 4) identified as evidence-based in the Individual Placement (IPS) and Support approach to supported employment in the U.S.A. [20]. The two major differences are: (1) initial access is based on Centrelink assessment followed by agency assessment of suitability, rather than consumer choice; and (2) there is little collaboration with mental health services, except in some locations where strong inter-agency relationships have developed.

As for IPS services, Australian open employment services offer rapid commencement of career planning, job research, job searching, and job placement with time-unlimited on-going post-placement support 
available if needed. Australian open employment services also have access to other supporting Government programs, in particular: (1) the Supported Wage System for accessing productivity based wages and productivity assessments; (2) Wage Subsidies (reimbursement of short-term wage subsidies paid to employers); (3) access to vacancies held in the Job Network; and (4) access to additional funds for workplace modifications. In addition, open employment services can assist people with disabilities already working and whose jobs are considered at risk, under the Job-in-Jeopardy program. Access to open employment services is controlled in three ways: firstly, by Centrelink assessing the eligibility of individuals, by each agency assessing the suitability of each applicant, and thirdly by capping the number of places available at each service under cased-based funding.

\subsection{Group-based employment services}

Originally developed from whole of life services and sheltered workshops for people with physical, sensory and intellectual disabilities, business services are funded to provide meaningful employment opportunities for people with disabilities. Each service is encouraged to achieve commercial viability. Token allowances were once paid to disabled workers. Services are now encouraged to pay wages at industrial award rates or according to productivity assessments under the Supported Wage System. Since the introduction of individual supported employment in the 1980s, group based programs have become philosophically unpopular with funding providers who prefer to fund individualised programs where a person's quality of life does not become too dependent on the relationship with a single agency.

Group-based programs such as business enterprises, Clubhouses, community co-operatives and mobile work crews, have applicability to people with mental illness. These can differ widely in design and in the range of career learning experiences provided. Social firms represent the latest evolution in group-based programs. These offer award wage jobs in a real business where a proportion of jobs (but no particular jobs) are reserved for suitable applicants with a psychiatric disability. Anecdotally, the advantage of group based programs are: the sense of belonging to a supportive community; social support from peers and staff; a protective low stigma environment; immediate prospects of structured activities including training or work; additional on-the-job supervision, training and support; access to social and recreational activities; advocacy services; and access to information about health and other community services. Some group-based programs (e.g. Stepping Stone and Pioneer Clubhouses) offer a range of complementary services at one location such as open employment, Job Network, personal support and supported education.

A limitation of group-based services is that only a limited range of career opportunities can be provided within any one business enterprise. In more transitional services, the person may become stuck at precompetitive levels of functioning prior to attaining competitive or open employment. Another fear sometimes expressed by funding providers, yet to be substantiated, is that the community formed around the service provider may prevent the person from utilising mainstream services and may limit social inclusion in the wider residential community. However, members of group based programs, particularly those where paid employment opportunities are available, often have few complaints and express high satisfaction with the services and the opportunities provided. This is also evident through reports of managers of group-based programs, that throughput can be difficult to achieve because workers with psychiatric disabilities, once adapted, often prefer to continue in their current form of employment. Further research is needed to identify the advantages and disadvantages of group-based programs in comparison to individual approaches to vocational rehabilitation.

\subsection{The Job Network}

The Job Network is a privatised network where the providers are private or non-government organisations contracted by government to provide a recruitment service for employers and a range of supporting labour market programs. Access to advertised vacancies is controlled by the provider. People with mental illness can access Job Network agencies directly or through disability employment and vocational rehabilitation services, but have reported unfair discrimination by being excluded from interviews for health reasons. 
Job Network staff have the least training in mental health, hence are more likely to have the lowest levels of mental health literacy. A recent official pilot study identified ways in which the Job Network can be enhanced to include people receiving the Disability Support Pension (DSP). This project included people with mental illness as part of the DSP group, and achieved improved outcomes for all project participants [91].

\subsection{Services provided by consumer organisations}

Another type of service often overlooked is the activity, education and advocacy centres run by mental health consumer organisations and schizophrenia fellowships in each State and Territory of Australia. Although these services may not have a designated role in employment, they can provide: (1) the means to communicate with and support consumers and their carers and families; (2) accurate information about mental illness, mental health, income support, and suitable community services; (3) information about local vocational services (for employment, education, training, and voluntary work); (4) a contact point for policy makers, vocational services, and researchers seeking to contact or consult with consumers; and (5) advocacy on a range of relevant issues, and encouragement for those seeking assistance with vocational rehabilitation. This type of service plays an important role in educating consumers, families, and carers about mental health and services issues, and can help educate professionals and service providers about current issues, systemic problems, and the unmet needs of people with mental illness and their families. Without such consumer organisations, people with mental illness and their families would be less informed, and fewer people than at present would succeed in accessing appropriate income support, community support, and vocational assistance.

\subsection{Public funded education and vocational training services}

Apart from those who experience cognitive deficits subsequent to mental illness or as treatment side effects, people with mental illness are generally not impaired intellectually. Given the frequency of education disruption and the importance of education to career development [14-15,54] it is surprising that in Australia neither Federal nor State Governments support disability-specific education assistance. In the U.S.A. several forms of specialised supported education have been evaluated. Specialised supported education for persons with mental illness is considered more effective than reliance on the generic disability support usually provided at education institutions [92-94]. This support can take the form of: support groups on campus; off campus support groups; or individual coaching and support both off and on campus. The key ingredient seems to be a coordinator trained specifically in the educational barriers facing persons with psychiatric disabilities.

Although supported education is sometimes funded in response to particular submissions, in specific locations, by various state and federal departments, there is no national initiative or agreed structure by which to provide specialised education and vocational services for people with mental illness. Clubhouses sometimes offer informal programs of supported education via regular meetings for members participating in formal study. Throughout Australia, individual training and educational institutions are required by anti-discrimination legislation to respond to the needs of people with disabilities, although the special needs of people with mental illness may not be recognised [54]. Nevertheless, people with mental illness can and ought to approach their local vocational training or tertiary education institution, but may have to provide additional information about their particular education restrictions in order to have their assistance needs recognised.

\subsection{Community mental health services}

In Australia, community mental health services are not resourced to provide vocational assistance. However, in line with National Mental Health Plan 2003-2008 [9], states and territories promote a recovery philosophy for mental health service delivery. Under this philosophy, rehabilitation services are sometimes provided alongside treatment and community support services, sometimes including prevocational, vocational and education support services. However, recovery outcome measures are 
typically confined to clinical dimensions of illness recovery and global assessments of social functioning. Dimensions of socially-valued role functioning are not usually assessed, identified or specifically supported [95-96]. Hence favourable outcomes in terms of improved socially-valued role functioning may remain undetected.

Community mental health treatment and support in Australia is not systematically linked to vocational rehabilitation or disability employment assistance [3]. This disconnection is also found in the U.S.A. In a survey of patterns of usual care for patients with schizophrenia [49], Lehman et al. found that among the unemployed outpatients, only $22.6 \%$ had vocational rehabilitation specified in their treatment plans or reported participating in a vocational program. Fewer than $25 \%$ of mental health consumers reported connections to vocational rehabilitation services. There is also evidence that psychiatric rehabilitation as provided within the public mental health system (i.e. segregated from vocational rehabilitation) does not improve employment outcomes [2,47].

One of the potential problems facing community mental health services in Australia is the absence of exit strategies for clients who are perceived as capable of more independent functioning. Anecdotally, mental health service staff routinely report the presence of clients who by their retention, limit the service outlet's capacity to assist new clients. A focus on employment and other socially-valued roles (e.g. education, selfdevelopment, or caring for others) can be used to motivate mental health self-management and promote exit strategies from public mental health support. This can be a natural progression in Australia because open employment services provide continuing support for employed clients, who may also prefer to see a private psychiatrist once regular hours of employment are established. Hence, a focus on employment and other socially valued roles within community mental health services can lead to the development of appropriate exit strategies.

\subsection{Psychiatric disability support services}

Independent living assistance, supported housing, disability and lifestyle support may be provided by state and territory governments independently of public health services (as in Queensland), or as an accepted responsibility of the public mental health sector (as in Victoria). In addition, Home and Community Care (HACC, a joint federal-state initiative) provides assistance to people with disabilities and their carers. This assistance can include nursing care; allied health care; meals and other food services; domestic assistance; personal care; home modification and maintenance; transport; respite care; counselling, support, information and advocacy; and assessment.

Disability support services are often provided via non-government organisations. Apart from Australian Government services (e.g. HACC and PSP - see 5.2), the availability of psychiatric disability support varies by state and territory, as does the nature and intensity of the services provided. In some states psychiatric disability support is rarely available, whereas in other states (e.g. Victoria) psychiatric disability support is well established and represents another service sector. Where disability support services are provided independently of mental health and vocational services, additional inter-sectoral difficulties can arise.

\subsection{The need for inter-sectoral partnerships}

The National Mental Health Plan 2003-2008 [8-9] and reviews of the national strategy [10-14] have identified the need to promote innovative inter-sectoral partnerships. Intersectoral partnerships were a key policy direction of the first National Mental Health Plan but translating that policy direction into enduring changes has not been actively pursued [8]. Intersectoral partnerships are considered critical to successful outcomes in community mental health care [14] because services other than health (e.g. housing, education, employment, criminal Justice) can have an overshadowing impact on the lives of people with mental illness. Inter-sectoral partnerships are needed to address difficulties in several sectors: employment, education, public mental health, private mental health, income support, and disability support. 
Inter-sectoral partnerships can be developed by encouraging community mental health services, or community disability support services, to provide a partnership structure such as systematic brokered referral to agencies funded to provide vocational and or educational services. Under this arrangement, each person's individual treatment and recovery plan could include vocational referrals. Hence in this example, referrals to suitable agencies could become systematic, regularly monitored, and strengthened by the mental health service providing mental health training for local vocational staff. Existing funding structures could support a shift towards establishing more effective, systematic and monitored links to appropriate vocational services.

Another approach, which has the potential to overcome the inter-sectoral difficulties outlined, involves integrating specialised individual employment assistance with community mental health support at one site. Co-location of mental health support and vocational services has been shown to facilitate collaboration and knowledge development in both sectors and can improve both clinical and employment outcomes of participants [20].

\subsection{Service evaluation and outcome measurement}

The utility and efficacy of Australian vocational services for people with mental illness remains largely unknown due to multiple disconnected programs and fragmented data collection. Australian Government Departments and agencies collect data of varied quality, independence, and researcher accessibility. Confidentialised high quality data sets are needed which link information about: diagnosis, role functioning, demographics, benefits and pensions, earnings, hours of employment, employment restrictions, and vocational services sought and received over time. At present the most suitable data are found in five yearly ABS national surveys, although limited information is collected about vocational assistance received.

Similarly, in the community mental health sector, role functioning and vocational activity variables are not routinely collected. Hence it is not currently possible to investigate the contribution of community mental health services to supporting vocational functioning. Data collection reform across sectors is needed to establish a common method for tracking individuals over time to ascertain the nature and extent of all relevant public funded assistance and the direct costs of that assistance. A promising data set is the FaCS and DEWR Longitudinal Data Set, which consists of a 1\% random sample of people receiving Australian Government income support payments. This data set could be enhanced by the addition of vocational variables and more precise specifications of disability and mental health conditions.

Improved and coordinated data collection is needed for describing the nature of disability support, income support, and employment assistance provided, which can then be linked to clinical and health outcome variables collected in the mental health sector, in a strategy common to all states and territories. Such a common and minimum data set would enable on-going evaluation of the efficacy and efficiency of disability employment, vocational rehabilitation, disability and personal support, and labour market programs, with respect to people with mental illness.

\subsection{Implications for policy development}

The main implication for policy development is the need for ongoing evaluation of existing vocational services in terms of effectiveness and cost-effectiveness for assisting people with mental illness. At present evaluation is ad hoc, consisting of occasional reports into specific programs. Hence, it is difficult to identify the effective programs, or the effective ingredients of programs that can lead to improved service development. Data collection reform across sectors, programs, and services is needed as a priority to enable high quality usable data to be collected which can be used for on-going service evaluation and service development.

Although the Australian Government's current generic approach to employment for people with disabilities is understandable on efficiency grounds, outcomes for people with mental illness are unlikely to improve unless disability-specific data are similarly collected across sectors. Although services to 
people with disabilities can be provided generically, improving processes and outcomes for people with mental illness requires a disability-specific approach because psychiatric disabilities, unlike other categories of disability, are typically fluctuating and episodic and often require on-going or periodic treatment, which needs to be coordinated with vocational interventions and activities.

Demonstration projects specialising in cutting-edge vocational services for people with mental illness are needed in a range of Australian urban and rural sites to assess the feasibility of more evidence based practices and the range of methods by which the inter-sectoral problems can be overcome. Such demonstration projects could also be used to identify data management issues to progress the development of common and minimum data sets.

In the meantime, funding policies can support a wide spectrum of promising and evidence-based ingredients derived from all promising service approaches to enable consumers to have a choice of suitable providers, and an opportunity to obtain a varied range of assistance. Although, group-based services have been the least researched and are the least favoured by more recent research on individual supported employment, it is premature to conclude that group based programs are not effective at advancing vocational recovery. The greatest risk of group-based services is that people get stuck at precompetitive levels and experience vocational stagnation. However, this risk can be countered by linking group-based programs to supported employment opportunities at the same location. In addition, groupbased services can utilise the new multidimensional scales of role functioning for tracking preemployment progress and alternative role activities to protect against vocational stagnation [95-96].

\section{How mental illness produces barriers to employment}

\subsection{Direct and indirect barriers to employment}

Psychiatric disabilities are both directly and indirectly associated with barriers to employment. Employment barriers can result from the positive, negative and disorganised symptoms of psychosis, from side effects of antipsychotic, mood stabilising, and anti-depressant medications, and from subsequent impairments to social skills, sense of self, personal confidence, and self-efficacy [97-98]. In addition, indirect barriers to employment can result from the negative experiences of stigma and unfair discrimination, and from the timing of illness onset, which can disrupt formal education and training, impede school-to-work transitions and damage the formation of work-values and core work-skills.

\subsection{Cognitive impairments as barriers to employment}

Mental illness can produce cognitive, perceptual, affective, and interpersonal deficits, each of which may contribute to employment barriers [98]. Of these, the cognitive deficits have more consistent association with unemployment [99-101] and poor work performance [52,102-103]. Cognitive deficits consistently found in schizophrenia or schizoaffective disorder include generalised deficits such as lowered full-scale IQ and a reduced capacity for information processing [104]. Green [105-106] found a wide range of both specific and general cognitive deficits in the majority of people with schizophrenia although a characteristic deficit profile did not emerge. Specific deficits can include problems with attention, sustained attention, memory and executive functioning [104,107].

Cognitive deficits received little research attention until recently [101]. Previous literature reviews may have discouraged the investigation of cognitive deficits through findings that cognitive functioning was inconsistent or non-predictive of employment outcomes [108]. However, an alternative explanation may be that cognitive deficits cause employment restrictions, yet many of these may have been neutralised by appropriate vocational choices, job matching, and other vocational interventions (see Table 1).

Recent studies indicate that cognitive symptoms are likely to cause employment restrictions [71,109], which limit occupational choice through restricting the type of work activities which can be successfully performed. Industry and job choices can be restricted, work hours and work performance may be limited, and the need for on-going assistance to retain employment may be increased [110-112]. In addition, 
general cognitive deficits as well as deficits in social cognition [113] are associated with impaired workrelated social skills, and may underlie the impaired social competence which can influence vocational outcomes [83,101,114-115].

\subsection{Other clinical symptoms as barriers to employment}

Almost all the clinical symptoms associated with mental illness can, at an individual level, directly contribute to employment barriers. As Rutman [98] notes, people with schizophrenia can present as personally unattractive and display socially inappropriate or unusual behaviour. The symptoms which may contribute to employment barriers include comorbid symptoms of anxiety and depression, personality difficulties, thought disorders (bizarre thinking, delusions), anosognosia, disturbances of perception (auditory hallucinations in particular), negative symptoms of apathy, inertia, anhedonia, alogia, disorganised symptoms, affect disturbances, and disturbances of communication [17,47,116-117].

In addition, clinical symptoms may impair social skills development although the precise mechanism remains unclear [114]. Exploratory studies have suggested differential roles for the major symptom clusters. For instance, Smith et al. [118] in a small study of rehabilitation readiness $(n=25)$, proposed that negative symptoms effect motivation, disorganised symptoms influence regular participation, and positive symptoms influence social functioning more so than the negative and disorganised symptom groups.

Psychiatric symptoms are potentially disabling and can vary over time, yet are not consistent predictors of vocational outcomes. Numerous investigations and several reviews [101,108,119-120] have found that few clinical variables predict employment outcomes at the individual level. Tsang et al. reviewed controlled studies between 1985 and 1997 and found in particular that diagnostic category and psychiatric symptoms were inconsistent predictors. The most consistent predictors of employment outcomes were found to be work history, premorbid functioning and current social skills.

More recent studies have found that longitudinal course patterns of illness can predict employment outcomes. In an examination of course of illness as a barrier to employment some authors [121-123] have used repeated formal assessments to derive course of illness type, which in turn predicted progress in vocational rehabilitation. Others [2,124-125] found that a less technical classification of course type based on self-report also predicted employment outcomes among people with schizophrenia. These findings support the differentiation of course patterns of psychotic illness over time, as an alternative to crosssectional symptom profiles, for predicting initial assistance needs in psychiatric vocational rehabilitation.

\subsection{The episodic nature of the disorders as a barrier to employment}

Mental illnesses can be episodic and fluctuating in nature despite optimal pharmacological treatment and good psychological and social support. The first and subsequent episodes can be frightening and traumatic experiences which damage a person's stability and identity, weakening their ability to commit to longer term endeavours such as vocational rehabilitation [98]. In addition, during relatively stable periods people can have their assistance needs underestimated by providers of housing, disability, income, family, and employment assistance, which can lead to refusal of services or under-provision of support, leading to adverse events causing frustration and hopelessness, further weakening the person's capacity to manage vocational challenges.

Reliance on clinical symptom measures can lead to the flawed conclusion that reduced symptoms indicate reduced employment or education assistance needs. A better way to assess career related assistance needs is to take account of predictors and correlates of employment outcomes, namely level of employment restrictions, lifelong course pattern of illness, premorbid functioning, educational attainment, relevant work history, relevant vocational skills, and current social skills [2-3,30-31].

\subsection{Treatment interventions as indirect barriers to employment}

Both pharmacological and psychological treatment interventions can produce additional barriers to obtaining and retaining employment. The known side effects of anti-psychotic, anti-depressant, and mood stabilising medications $[98,126]$ and the time taken to establish optimal medication type and dosage, can 
cause difficulties for the provision of vocational assistance. In addition, sub-optimal treatment can contribute to poor adherence, which in turn can exacerbate symptoms, interfere with planned treatment, and undermine vocational interventions.

Treatment and vocational rehabilitation interventions need to be coordinated so that changes to treatment plans (e.g. a new medication trial) do not conflict with planned vocational activities. Sometimes treatment goals need to be balanced by vocational goals. For instance, some residual positive symptoms may be preferred to a symptom free state with lowered energy levels, insufficient to sustain preferred hours of employment. Failure to actively coordinate interventions by treating and vocational professionals may create a coordination barrier to employment, placing the onus on the person least likely to manage this responsibility, to coordinate treatment interventions with rehabilitation activities.

Psychological and psychosocial treatments are now commonly used in support of pharmacological treatments. Cognitive behavioural therapy [127], cognitive remediation [105], psycho-educational family therapy, assertive community training [127], family and peer support [1], motivational interviewing [128], pre-vocational interventions such as illness management and social skills training [129] and structured feedback on work-performance [130] are now available. Recent reviews suggest that when used appropriately, these interventions can contribute to symptom reduction, reduced relapse and improved psychosocial rehabilitation outcomes. However, these programs are not without risk. Participants may develop dependency on the programs or the practitioners offering the services [98] or may become stuck in the role of client or impaired person and may resist moving on in the rehabilitation process [131].

\subsection{Low vocational expectations by health professionals}

Blankertz and Robinson [132] believe that health professionals' low vocational expectations of service users is a major problem because it prevents the majority of people from receiving vocational rehabilitation and supported employment services. Mental health professionals often report that people with psychiatric disability have unrealistic work expectations and goals [133]. In examining programs with low rates of people with psychiatric disability in competitive employment, it was found that the onus was left on individuals to bring up their interests in employment with the service provider. In addition, service providers tended to emphasise prevocational programs devoted to job preparation, did not pursue rapid assessment to capitalise on the service user's motivation for work, had limited contact with vocational services, had little direct employer contact, and provided minimal support to people once they were in employment [134].

\subsection{Community stigma as a barrier to employment}

In general, the public does not understand the impact of psychiatric disability and frequently fears people with these disorders. Members of the community withhold opportunities related to housing, work, and community participation [7]. People with psychiatric disability have fewer opportunities to work than the general population, mostly owing to the many misperceptions and prejudices about their abilities and needs. They are not expected to work, and indeed they are often considered not fit or well enough to work [135]. The lack of work serves to reinforce negative stereotypes and social exclusion associated with psychiatric disability. By not appearing within employment settings, it is mistakenly believed that people with mental illness are too incapacitated to work [135]. An additional issue is that some people with mental illness also endorse stigmatising attitudes about psychiatric disability. This internalised stigma affects the individual's self-perception and has the potential to impact on the success or failure of employment opportunities [136].

Community stigma and unfair discrimination are frequently reported by people with psychiatric disabilities [85,137] as adding to the difficulties of obtaining and retaining employment. The extent of past stigma experiences and reactions to those experiences can influence personal decisions about whether or not vocational goals are adopted. In addition, past stigma experiences may exert a strong influence on disclosure preferences throughout psychiatric vocational rehabilitation [76]. For example, an avoidant 
disclosure strategy influenced by negative disclosure experiences can create additional barriers to employment through limiting the provision of workplace accommodations. To overcome the adverse effects of prior community stigma, vocational professionals can provide stigma assessment and counselling, and develop ongoing stigma countering and disclosure strategies within each individual's vocational rehabilitation plan.

\subsection{Stigma among helping professionals as a barrier to employment}

Community stigma is sometimes exacerbated by unhelpful attitudes among health professionals and vocational professionals, expressed as undue benevolence or authoritarianism, or an unsubstantiated belief that employment is either not feasible, will adversely effect mental health, or is not a mental health provider priority $[69,76]$. This is common in Australia, where due to sectorisation, few clinicians become involved in specialised vocational rehabilitation, and hence do not get to see the positive and life-changing outcomes that can be achieved. A clinician's illusion can prevail, that people with mental illness cannot work, if clinicians only see those patients who are admitted to hospital or who are chronically relapsing. Specialised vocational professionals can help reduce this form of stigma by involving clinicians in the process and outcomes of vocational rehabilitation, and by informing mental health professionals and nonspecialised vocational colleagues about the methods, outcomes and efficacy of specialised vocational rehabilitation.

Among vocational professionals, stigma can manifest as a reluctance to assist people with psychiatric disabilities if staff lack confidence or are inadequately trained to assist this category of disability. The pressure on staff to achieve employment outcomes is likely to favour the selection of clients with more familiar and stable health conditions. The lack of a requirement to complete accredited training in psychiatric vocational rehabilitation, means that rehabilitation expertise is unlikely to be well distributed throughout the vocational sector. Consequently, people with mental illness may be unfairly excluded from vocational assistance, have their support needs incorrectly estimated, or may not receive suitably intense or continuous forms of assistance.

\subsection{Comorbid disorders as a barrier to employment}

People with mental illness co-morbid with other health conditions or disabilities, may be more likely to be excluded from vocational assistance through being perceived as too difficult to assist. This appears to be a workforce training issue, because overseas evidence [20] indicates that comorbid: substance use disorders, personality disorders, physical health conditions, intellectual disability, acquired brain injury, or mental illness associated with a forensic history, are not valid grounds on which to deny people access to vocational services. In Australia the anecdotal evidence suggests that people with comorbid disorders are more likely to be denied assistance, even by services which specialise in psychiatric disability. People can be easily excluded from vocational assistance in Australia because the service provider makes the final decision on acceptance into the more intense forms of assistance. Research is needed to investigate the extent that people with more severe and complicated forms of mental illness are able to equitably access appropriate vocational services.

\subsection{Workplace stigma}

The attitudes of employers towards people with mental illness may reflect the ignorance and stigma prevalent in the wider community [76]. This then may result in the belief that people with mental illness are unable to work, or that it is not possible to accommodate psychiatric disorders within the workplace. Negative employer attitudes have a number of implications, including that an employer will not hire a person with psychiatric disability or advance or retain people with these disorders [86]. When a person with a mental illness is hired, they may be treated differently from other workers. For example, Murphy [138] reported that people with psychiatric disability faced discrimination and prejudice by employers and co-workers once they knew the person had a disability. This included that the employer began to be afraid of the person, verbal abuse, harassment, and belittling the person's ability and judgement. 


\subsection{Confusing terms, definitions and measures as barriers to employment}

Conflicting descriptions and definitions of mental illness and psychiatric disabilities and multiple overlapping mental health terms create confusion among policy makers and service providers, often preventing the different service systems from adequately responding to the needs of individuals and sometimes creating tension between different service systems [98]. This can happen in Australia where income support or vocational service staff with less mental health training may fail to differentiate the level support needs among people with mental health problems from more severe clinical conditions which may need more intensive and more continuous employment assistance.

Furthermore, there are no widely accepted systems for classifying level of disability, assessing workreadiness, or for assessing level of need for vocational assistance. Hence, the need for vocational assistance may not be well matched to the vocational services provided. This problem is particularly evident in Australia where eligibility for public funded community mental health services, income support payments, personal disability support, disability employment assistance, and vocational rehabilitation, are determined by service providers using independent criteria which can confuse consumers and their families, and which may be unrelated to a person's actual level of disability and employment restrictions $[3,16,30]$.

\subsection{Government funding structures as barriers to employment}

At present, state-federal funding arrangements and departmental responsibilities define mutually exclusive roles, which form additional barriers to employment service delivery when health, education and employment services are required across multiple sectors and agencies simultaneously. With respect to employment, there are opportunities to improve outcomes by pooling rather than fracturing the acquired expertise. Community mental health knowledge (e.g. familiarity with the latest treatment methods and understanding day to day illness management) could supplement the specialised employment and vocational rehabilitation expertise acquired in the vocational sector.

For instance, a person with a mental illness may receive help from a Clubhouse, a specialised or generic open employment service, or from CRS Australia to prepare for work, and may need access to vacancies held by a Job Network agency when job searching. To retain employment, ongoing help may be needed from an Open Employment service. In addition, a TAFE College may be assisting with tailored vocational training to improve employment prospects, or as part of a traineeship package. These programs need coordinating. However, unless one provider can adopt a coordination role, the onus for coordination, by default, falls on the person least able to perform this role, the person with a mental illness. Without proactive coordination of essential multiple services, the stigma literature suggests that inadvertent program exclusion is the most likely outcome, especially if service staff have low mental health literacy [76].

Another type of barrier to employment may be created by case-based funding for disability employment services, CRS Australia, and for the Job Network. Although a method is in place via Centrelink to independently assess support needs to several levels of funding, the total number of places is capped for each disability employment service. When demand exceeds the places available, a barrier to employment is created because the final admission decision is the service responsibility. Hence, the capping of places can allow some services to rarely accept new clients. This can happen because a substantial proportion of people with more severe mental illness, through the fluctuating nature of mental illnesses, may have previously discontinued participation, or failed to achieve an employment outcome. Such inactive cases can often be reactivated, enabling the service to re-admit a well-known client, and avoid admitting an unknown and potentially more challenging client. Anecdotal reports indicate that people with more severe forms of mental illness have difficulty accessing the most suitable forms of vocational assistance in Australia. This is supported by evidence from a recent national survey where no persons with psychotic disorders [3], and only $2.5 \%$ of people with anxiety disorders of working age [30-31] were receiving job placement assistance. 


\subsection{Disincentives in the health and income support systems}

Another systemic barrier to employment is caused by work disincentives within the health, social welfare and income support systems [98]. This may be particularly important for people with psychiatric disabilities because of the difficulties qualifying for income support due to the episodic nature of the disorders and the greater difficulty with employment retention compared to other disability categories. In the U.S.A. health benefits associated with income support may be lost when part-time employment is obtained without employer sponsored health benefits. To find solutions to these potentially strong disincentives, Bond [20] recommends special attention be given to health and welfare benefits counselling in the early stages of vocational assistance.

Similar disincentives occur in Australia even though more substantial income support and public health services are available compared to the U.S.A. A recent study [91] found several disincentives acting as barriers to employment for those receiving Disability Support Pension (DSP). These included anticipated difficulty re-establishing entitlement to DSP; lack of knowledge of DSP suspension arrangements, lack of knowledge of earnings credits and applicable income tests; and lack of knowledge of assistance available to obtain employment. People surveyed also reported uncertainty about the type and amount of work their disability would enable them to perform [91].

\subsection{Rural and remote locations as barriers to employment}

Although health and vocational services are available throughout Australia, those living in rural and remote locations can be more disadvantaged by reduced availability of: public mental health services, private psychiatrists, general medical practitioners, disability employment services, vocational rehabilitation and Job Network services. In addition, career opportunities can be restricted to pastoral, mining and rural service industries. Relocating to improve access to support systems and employment opportunities can be difficult for people with mental illness who may need to live near families, friends and relatives to obtain sufficient social, economic and health support. The lack of services in some geographical areas can mean that only general health services are available, and vocational services may be unavailable or limited to one Job Network provider with staff untrained in psychiatric disability.

\subsection{Career immaturity as a barrier to employment}

Mental illness can create unique individual experiences which can lead to inappropriate values, attitudes and aspirations regarding work and careers [98]. Impaired work values and impaired perceptions of current work skills can cause unrealistic vocational goals, where perceptions of own work skills may diverge from actual skill levels and experience. These experiences may also represent career immaturity $[131,139]$ thought to result from the lack of exposure to typical life experiences, responsibilities and roles which help a person form appropriate work perceptions, work confidence, work interests, work values and work ethics. Although the precise psychological processes are unclear, it is likely that career maturity is influenced by the person's life experiences, personality, perceptions of illness experiences, family background, educational attainment, work values, and knowledge of workplaces and employer requirements.

\subsection{Subjective experiences and personal resources as barriers to employment}

Internal barriers to achieving vocational goals include unpredictable sleeping patterns, fear of failure, fear of relapse, lack of confidence in vocational abilities, difficulties with concentration, and fear of resuming work after years of unemployment [7,140]. In addition Waghorn et al. [141] found that a range of varied subjective experiences perceived to impact on work functioning, and self-efficacy for specific workrelated activities were closely associated to employment status.

Mallick, Reeves, and Dellario [142] found that financial resources, employment resources, and vocational skills presented the greatest barriers to community integration. Financial resources included money to meet financial obligations such as rent, food and other daily expenses. Employment resources were employment opportunities and available resources to find a job and maintain employment. Waghorn et al. [143] found that self-efficacy for core employment activities includes, career planning, job securing skills, 
job-retaining work skills (e.g. start work soon after arriving, complete tasks in the time required, identify and correct own mistakes), and job-retaining social skills (e.g. can follow instructions without resistance, can cooperate with co-workers to perform a group task, can check instructions with supervisors).

\subsection{Implications for policy development}

The barriers to employment among people with mental illness can be extensive. Collectively these are unique to each individual. Employment barriers cannot be precisely predicted from symptom profiles and diagnostic categories, and are often exacerbated by community stigma, including the stigma perpetuated by helping professionals. The main implication for policy development is that the specialised vocational knowledge needed for identifying and overcoming barriers to employment among people with mental illness, needs to be available to staff of non-specialised vocational services, employers, consumers, carers, clinicians and mental health staff in community health care settings. Hence, much can be done to educate these groups about how barriers to employment are overcome throughout the vocational rehabilitation process. Funding providers do not currently allocate resources for staff training in this area with the possible consequence that people with psychiatric disabilities may be unfairly refused assistance through being incorrectly perceived as unable to succeed in vocational rehabilitation.

The capping of more intensive places appears to create additional barriers to employment which need to be investigated further. It is possible that capping, combined with the policy of allowing each service to make final admission decisions, only results in recycling of clients well known to the service and prevents access by clients who have not previously sought or received vocational assistance. It would be interesting to know the extent that people with mental illness receive multiple services to little effect, and whether some services avoid clients with more severe employment restrictions.

\section{Evidence-based vocational interventions}

\subsection{The range of vocational interventions}

Various vocational interventions suitable for people with psychiatric disabilities have evolved over time. These are reviewed elsewhere [19-21,84,144]. Although each approach to vocational assistance has its advocates, a positive development in the literature is a new focus on the ingredients of effective vocational rehabilitation specifically designed for people with psychiatric disabilities. This development transcends the unproductive model-versus-model debate. Vocational interventions for people with mental illness have included unpaid voluntary work [84]; the Boston University psychiatric rehabilitation model (Choose-GetKeep) with extended pre-vocational career exploration; job clubs [84,145]; the program of assertive community treatment (PACT) [84,146]; generic supported employment [84]; Clubhouse transitional employment; specialised supported employment (also known as the Individual Placement and Support model of Supported Employment); generic vocational rehabilitation; and specialised vocational rehabilitation $[16,144]$.

In addition, there are promising group-based interventions such as business services (sheltered workshops), work-crews, community co-operatives and social firms. These services are usually designed to increase employment opportunities for people with disabilities by providing supportive and low stigma work environments, and by producing goods or services in order to pursue employment as a social justice mission. In social firms, a more recent development in Australia, the proportion of disadvantaged workers does not exceed $30-50 \%$ and every worker is paid industrial award wages or a productivity-based wage. Both disabled and healthy workers are intended to have equality in terms of opportunities, rights and responsibilities.

Australia also has a supported wage scheme [16] which enables an industrial award to be modified by a person's measured productivity in a particular job on a pro rata basis. Independent assessors can be arranged at no cost to the employer and the worker with a disability can have their performance assessed and reviewed on a regular basis to ensure that wages continue to match productivity. 


\subsection{Principles of specialised supported employment}

Specialised supported employment [147-149] is important for both its evidence base of randomised controlled trials and day centre conversion projects, and for the empirical identification of its underlying theoretical principles. Previously known as the Individual Placement and Support (IPS) approach to supported employment, evidence is accumulating that this form of specialised supported employment is effective for $40-60 \%$ of volunteers [20,150]. A consensus is emerging as to the evidence base for each of seven principles while research efforts continue to identify program enhancements. According to reviewers [20] there is consistent evidence for the first four of the following seven principles, while the evidence for the latter three remain relatively weak:

(1) Eligibility based on consumer choice;

(2) Integration of vocational rehabilitation with mental health care;

(3) A goal of competitive employment;

(4) Rapid commencement of job search activities;

(5) Services based on consumer preferences;

(6) Continuing support to retain employment;

(7) Income support and health benefits counselling.

Service eligibility is based on consumer choice [151]. No attempt is made to screen out participants on other than individual preferences and motivation. This approach has been found to be more effective when integrated within the mental health treatment team $[49,134,152]$. Integration is considered advantageous in four ways: (1) better engagement and retention of clients; (2) better communication between employment specialists and clinicians; (3) education of clinicians about employment issues; and (4) incorporation of clinical information into vocational plans [153].

The main goal is competitive employment rather than participation in day programs or sheltered work, which are usually not provided. The evidence suggests that interventions not focussing directly on competitive employment have little or no impact on competitive employment outcomes [20]. In addition, competitive employment outcomes are more desirable and recovery oriented than other forms of paid employment [20].

The early use of supported job searching and job placement whenever possible is considered important to prevent people losing interest in the necessary elements of job preparation and training in specific job skills. Although empirical support for rapid job searching is strong $[19,21]$ it is not yet a widespread practice among other vocational services in the U.S.A. For instance, a recent study of a Clubhouse program found that the average time prior to the first transitional employment placement was 356 days [154].

Other interventions when provided, are provided in parallel not in series with job searching or job placement. Bell et al. [130] found cognitive skills training provided concurrently with supported employment, was a successful parallel intervention which need not delay either job searching or job placement. Both treatment and vocational interventions are tailored to the type of job searching or work tasks required [20].

Services provided are based on consumer preferences, strengths, prior work interests and experiences rather than on a pool of available jobs. The evidence shows that the majority of clients have stable and realistic job preferences [155] and jobs matched to initial job preference had a longer job tenure than those not so matched [156].

Follow-on support is available continuously over time with no closure date, so that on-the-job or behindthe-scenes support is available when needed. Employment specialists stay in regular contact with clients and employers without arbitrary time limits, although the intensity of support may reduce to a maintenance level of regular contact only. McHugo et al. [87] found supporting evidence at 3.5 years from commencing employment, where $71 \%$ of those who continued receiving support were still employed, 
compared to $28 \%$ of those who had discontinued support. Support is provided proactively. Assistance is not withdrawn denied punitively to people who fail to attend appointments or who do not achieve agreed milestones. Support is actively provided in partnership with the person with a mental illness.

Health and welfare benefits counselling is provided although the current supporting evidence is relatively weak [20]. Consumers are helped to make well-informed decisions about their entitlements to welfare benefits and health insurance coverage to ensure that benefits entitlements do not add unnecessary disincentives to employment.

\subsection{Unique principles of transitional employment}

Although on-site support is commonly provided in supported employment and vocational rehabilitation, an important and unique principle of Clubhouse transitional employment programs is the continuous availability of intensive on-site support [157]. This aims to overcome employment barriers in the workplace by demonstrating core work skills and appropriate work behaviours, using on-site training to teach and reinforce good work attitudes, behaviours and performance. Consequently, the close relationships formed between Clubhouse staff and employers enables a suitable training environment to be created for assisting new members at work, and for countering stigma by educating others in the workplace about mental illness and mental health.

Transitional employment is a form of psychiatric vocational rehabilitation developed specifically for people with psychiatric disabilities $[50,78,154,158]$. Intensive forms of on-site assistance are routinely provided at each entry-level job held by the Clubhouse. Staff members learn the job in order to perform the duties on days when the member or members selected to perform the job for a specified period are unwell or unable to attend. The aim is to provide members with real employment experiences (paid at award wages) to overcome career immaturity and to help people form and test career goals. Transitional employment placements are typically part-time, linked to prior participation in Clubhouse day programs (the work-ordered day) and limited to a duration of 4-6 months, to enable other members to share the available opportunities. Clubhouses may also offer housing, social recreation, and supported education programs [159].

Although not formally identified as contributing to employment outcomes, the Clubhouse member-based organisation provides an appropriate infrastructure for people with mental illness. Like social firms, Clubhouses provide safe, low-stigma environments, which encourage vocational recovery and support general illness recovery through peer support, sharing of resources, and increased social and recreational opportunities to help rebuild personal and social confidence.

\subsection{Unique principles of specialised vocational rehabilitation}

In a recent comparison of the CRS Australia service model with the effective ingredients of supported employment, McDonald [84, p. 64] argued that the allied health professionals employed by CRS Australia in the three sites specialising in psychiatric disability, represent the provision of another service ingredient, the multidisciplinary team [160]. McDonald states that the multidisciplinary team provides a form of coordinated mental health care and vocational services through team members being typically experienced in mental health treatment, and through close liaison with the client's treatment professional. In addition, allied health professionals on the team design supplementary interventions often deriving from cognitive behaviour therapy, narrative therapy, motivational interviewing, and observations of vocational behaviour. These interventions aim to reduce employment restrictions and improve independent functioning, work attitudes, and work performance. Anecdotal reports suggest that these interventions, through added employment motivation leverage, can be more successful than when provided in a general health or psychiatric setting.

The rehabilitation alliance appears to contribute to service effectiveness in vocational rehabilitation although this has not yet been identified as an evidence-based ingredient of supported employment. The rehabilitation alliance is based on a shared understanding of both the staff member's and the consumer's roles in rehabilitation. Vocational staff undertake to provide timely and proactive assistance according to 
mutually agreed needs for assistance which are constantly reviewed. This usually involves active outreach, where meetings can take place in the consumer's local environment, and follow-up action is initiated immediately problems occur, such as when appointments are missed, in order to promptly provide any additional assistance needed. The rehabilitation alliance is supported by evidence in non-specialised vocational rehabilitation that strong partnerships, as rated by both staff and clients, are associated with better client employment outcomes [161-164].

\subsection{Emerging candidates for evidence-based components}

The use of explicit strategies to counter workplace stigma, and structured counselling to optimise disclosure strategies, are also expected to enhance outcomes in psychiatric vocational rehabilitation by improving job commencement and job retention. Although there is not yet any clear evidence to support this strategy, the fact that job retention remains the major challenge in all vocational approaches, indicates this item warrants inclusion in Table 1. Some people may fail to seek, obtain, or retain employment, because of past stigma experiences [165] or previous work-place discrimination [86]. Hence, strategies are needed throughout vocational rehabilitation [76] to counter past and present stigma and strategically manage disclosure of personal mental health information in the workplace.

To prevent negative stigma experiences in a particular workplace, a plan for workplace education can be developed along with the vocational rehabilitation plan. Initial education can be provided to increase mental health literacy generally and to counter stigma-based beliefs prevalent at the supervisor and manager level [86]. Mental illnesses such as anxiety disorders, depression and even schizophrenia can be discussed in the context of occupational health and safety, the work environment, and general mental health and wellbeing, which are topics of interest in most workplaces. Ongoing support plans for the individual can encompass a plan to increase mental health literacy, and prevent and counter stigma in the workplace over time. This can be achieved by: (1) facilitating co-worker social interaction; (2) teaching specific work-related social skills to the worker with the mental illness; (3) the use of peer support arrangements; (4) ongoing strategic and ethical disclosure of health information relevant to work performance; and (5) by planned ongoing education of employers, supervisors, co-workers, and third parties throughout the vocational rehabilitation process [76].

However, some people may report such negative stigma experiences that they are currently unwilling to consider an open employment placement. For these people, stigma-safe environments may be needed to enable rebuilding of work and social confidence. Hence to meet a broad spectrum of assistance needs, alternatives to open employment approaches such as transitional employment, business services, social firms and community cooperatives, can contribute by providing low-stigma work environments as a bridging option towards open employment.

\subsection{Principles of effective vocational services in-use in Australia}

The evidence-based and unique ingredients of specialised supported employment, transitional employment, and specialised vocational rehabilitation indicate the distribution of empirical principles underpinning vocational services in Australia (see Table 4). Of the eleven principles shown, six are provided by open employment services, six by CRS Australia, five by transitional employment, and three by the Job Network. One principle (the rehabilitation alliance) is sometimes provided by Community Mental Health services in Australia. The principle in the last row of Table 4 (stigma and disclosure strategies) may be addressed when issues arise, but is not known to be routinely provided as a formal strategy to support vocational activities.

\subsection{Implications for policy development}

Research into the effectiveness of vocational rehabilitation of people with mental illness has recently begun to focus on service ingredients and how each contributes to vocational outcomes. Most research has been conducted with respect to specialised supported employment in the U.S.A. However, promising ingredients are emerging from other approaches, which warrant further investigation (see rows 8-11 of Table 4). 
Funding providers can plan vocational service development for people with mental illness by funding a broad mix of evidence-based ingredients (see Table 4) within each local region. This approach avoids the counter productive model versus model debate, and promotes funding for both emerging and established evidence-based ingredients in psychiatric vocational rehabilitation.

\section{Linking vocational interventions to mental health care}

\subsection{The impact of untreated psychosis}

The disruptive and disabling effects of first episodes of psychosis coincide with the maturational issues of mid to late adolescence and early adulthood. Most psychotic disorders occur between the age of 10-30 years, a critical developmental period in the lifespan, in terms of social and emotional wellbeing [166]. Young adults need to gain independence from their families, develop interests, hobbies and social skills, discover and experiment with sexuality, form and maintain relationships; and make the transition from secondary school to employment or further study [167]. The onset of a mental disorder can threaten sense of self and identity, delay maturity, disrupt valued roles and degrade social status.

Untreated psychosis affects social, psychological and biological domains [167]. Interpersonal relationships, education, employment, and accommodation stability may be affected. Psychologically, young people with untreated psychosis may experience fear, despair, demoralization, loss of selfconfidence, anxiety, difficulties with personality development, depression, and have an increased risk of suicide. Biologically, untreated psychosis is associated with reduced rate and level of recovery, increased risk of poor physical health, increased risk of substance and poly-substance misuse $[167,168]$, and increased risk of life long problems in mental health and social well-being [166].

\subsection{Vocational interventions as part of an early intervention approach}

Early intervention is increasingly seen as having the potential to produce better outcomes for people with psychotic disorders. Effective early intervention offers the hope of restoring normal social and psychological development [169]. Early intervention can: decrease disruption to the family, education and employment; decrease the need for inpatient care; decrease relapse risk; lower risk of suicide; and can reduce the total cost of treatment [167].

An early intervention framework requires a shift from the more traditional medical model and treatment approach to one which focuses on individual empowerment, individual strengths, and building individual capacity for community participation. A wellness promotion approach can be used to focus on enhancement and optimisation of positive functioning. Creating opportunities for people to exercise existing capabilities as well as developing new competencies is central to empowerment models. Utilising a strengths-based approach recognises the assets and talents of people and helps people to use these competencies to strengthen functioning. Resource-based approaches are also applicable. These utilise a broad range of community opportunities and experiences [166].

For effective early intervention, service providers need to identify those likely to be experiencing an early stage of illness or a first episode of psychosis, and need to be alert to factors (e.g. substance misuse) which can precipitate illness, personal crises, and illness relapse. Early intervention service providers typically work within a multidisciplinary team framework [170] and are able to engage with young people experiencing early psychosis and their families. To include adequate vocational interventions as early interventions, service providers may either employ vocational specialists, or obtain a detailed knowledge of local sources of assistance suitable for helping young people continue with education, vocational training and employment. An advantage of including a vocational dimension with early mental health interventions is that expectations for career path recovery can be maintained and the problem of low vocational outcome expectations by clinicians can be avoided. 


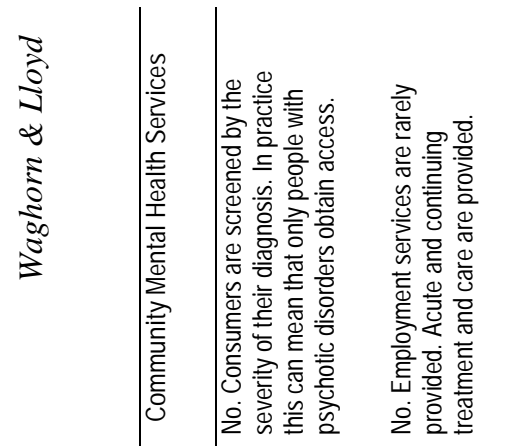

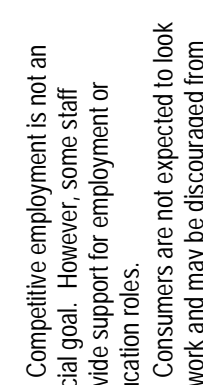

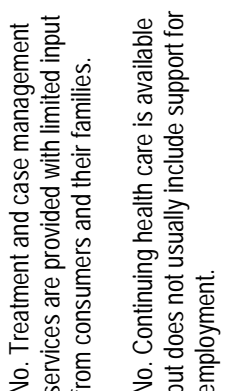

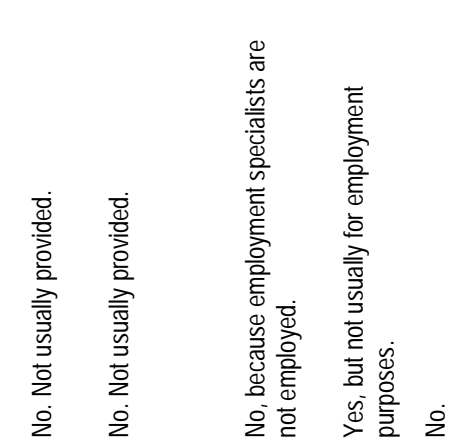

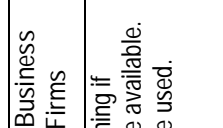

要类

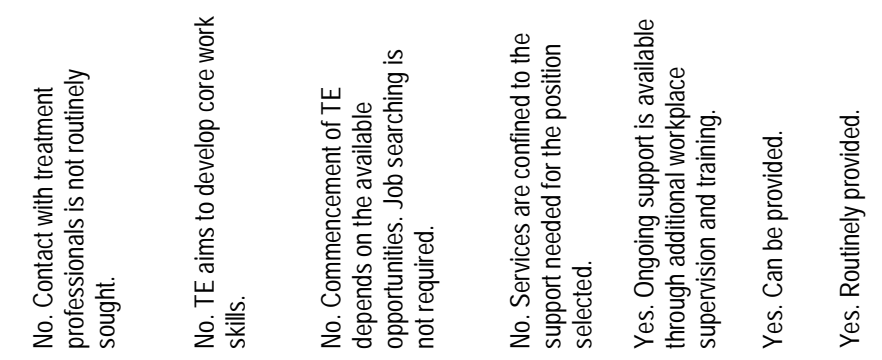

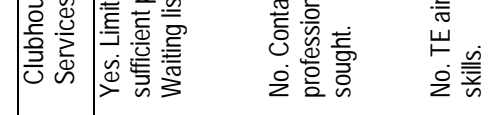

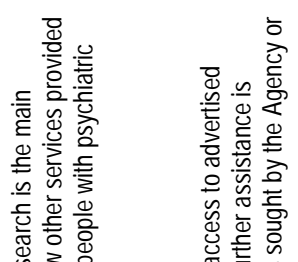

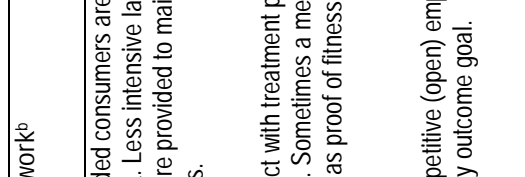

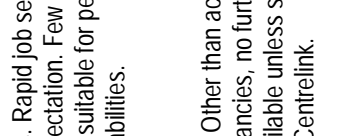

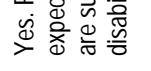

之⿺ 丶万

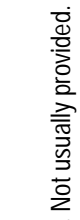

齐

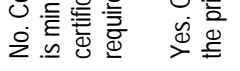

C)

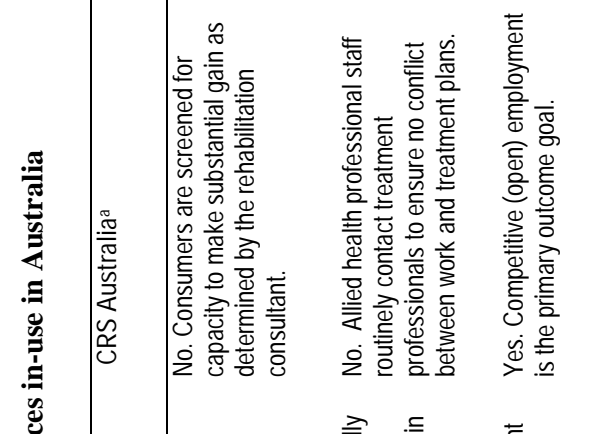

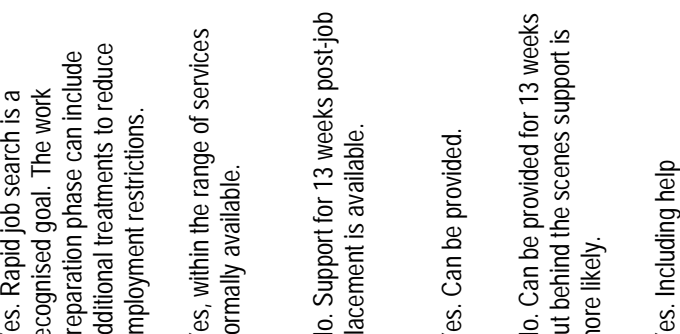

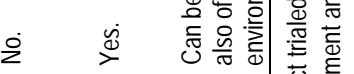

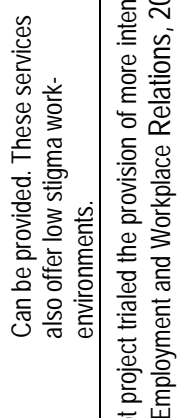

和

产岩

要

零

离 


\subsection{Vocational interventions and a recovery framework}

Recovery is defined as the process of overcoming symptoms, psychiatric disability, and social handicap. It can involve a redefinition of the self, the emergence of hope and optimism, empowerment, and the establishment of meaningful relationships with others [171]. Recovery is oriented towards the reconstruction of meaning and purpose in one's life, the performance of valued social roles, the experience of mental health and well-being and life satisfaction. It means maximizing well-being within the constraints imposed by health status. A recovery framework incorporates continuing care with relapse prevention plans and psychosocial rehabilitation [172]. The lived experience of the person with the mental illness is also acknowledged and attempts are made to maximise their wellbeing along with that of their family [172].

As an evidence-based form of psychosocial rehabilitation vocational rehabilitation is ideally suited to a recovery framework. Recovery planning can incorporate a discussion of preferred socially-valued roles, and if vocational roles are chosen, vocational activities can become the focus of the recovery plan. Anecdotal reports indicate that recovery plans that include vocational activities can deliver new opportunities to observe signs of both recovery and deterioration in mental health, and help prevent relapse, because deterioration is often first observed in vocational rehabilitation activities or in work performance. A comprehensive recovery plan can also include crisis planning, a list of things that people have done in the past to help themselves to stay well, and a list of things they could do to help themselves feel better when things are not going well [172].

\subsection{How employment and education contribute to recovery}

Having a reason to get out of bed and to have something meaningful to do during the day is essential for the wellbeing of people with psychiatric disabilities. Work has an important role in the recovery of people with psychiatric disabilities and many of the goals of rehabilitation are best served by addressing the person's vocational aspirations [7]. Employment contributes to the recovery process through being perceived as a means of self-empowerment, and by promoting a sense of self-actualisation [140]. Meaningful activities can also contribute to the recovery process, through active participation in structured social, recreational, volunteer work, arts, and education.

Assisting people with mental illness to participate in education through the use of specialised strategies for psychiatric disabilities is known as supported education. Supported education has been investigated extensively in the U.S.A., and when tailored specifically for people with mental illness, can contribute to career development. A recent longitudinal study [52] and a secondary analysis of data from the USA National Health Interview Survey on Disability, 1994-95 [53], linked educational attainment to increased employment outcomes and higher employment status in the U.S.A. In Australia, educational attainment is closely associated with employment outcomes. Two national surveys [2,54] found positive links between educational attainment and both current employment and durable employment among people with psychotic disorders. Among those not completing secondary school, $11.6 \%$ of people with psychotic disorders reported current employment. The employed proportion increased with secondary school completion (22.1\%), vocational qualifications (34.3\%), and attaining Bachelor degrees or higher (46.7\%). There is also evidence that supported education contributes to community integration [173].

\subsection{Implications for policy development}

Vocational interventions are suited to integration with early intervention and relapse prevention strategies in the mental health sector. The provision of vocational assistance, even by brokered referral, can support a recovery based approach and help prevent social and economic marginalisation by attempting to preserve vocational roles or restore vocational functioning as soon as possible following illness onset. Each person accessing public mental health services can be assisted with a comprehensive recovery plan which takes into account personal goals, treatment goals, education and vocational goals, along with specific action plans for the next 1-5 years.

The need to restore educational attainment following disruption by mental illness is recognised by the National Mental Health Plan 2003-2008 [9, p. 22]. However, this need was overlooked by Australian welfare, vocational rehabilitation, and disability employment service reform throughout the 1990s which 
addressed obtaining employment to the exclusion of higher education and substantive vocational training. More specific strategies are needed to provide supported education for people with mental illness over and above the disability assistance currently available to all disability groups via education and vocational training institutions.

\section{Conclusions}

\subsection{Summary of findings}

The key findings from this report are consistent with and support the previous findings of Bulletin 3 of the recent national survey of mental health and wellbeing [55]. The key findings are:

(a) Equitable access to career opportunities is a right of Australian citizenship;

(b) Career pathways are not restored by mental health care alone;

(c) Governments have an obligation to address the extensive social and economic marginalisation associated with mental illness;

(d) Strategies are needed to enable and encourage labour force participation throughout the whole working life;

(e) Older people with mental illness can have additional and complex assistance needs;

(f) Employment restrictions and low educational attainment impact on labour force participation and employment;

(g) A substantial proportion of people with mental illness have both the capacity and desire to work;

(h) Employment is feasible even for those with severe to profound employment restrictions, provided suitable forms of assistance are provided;

(i) Disability-specific supported education strategies are needed;

(j) Support is needed for socially-valued roles other than employment, to help people gain a valued place in the community;

(k) Employment can contribute to mental health and can help reduce the community-based stigma experienced by people with mental illness;

(1) Employment is highly valued by some individuals and can have positive life-changing consequences;

(m) Transitional arrangements are needed for those who are not yet ready for competitive employment;

(n) A coordinated data collection strategy is needed to support ongoing service evaluation, the development of innovative services and high quality research. More information is needed about the type of mental illness or psychiatric disability, whether co-morbid health conditions are present, the level of employment restrictions reported, the nature of assistance provided, and whether other forms of vocational assistance are being provided or were provided in the past year;

(o) Multidimensional role functioning and role satisfaction measures can protect against vocational stagnation in transitional services where the vocational goal does not yet extend to open employment;

(p) Both the vocational and mental health workforces could benefit from accredited formal training in psychiatric vocational rehabilitation;

(q) Barriers to employment are numerous. Although some are directly caused by mental illness and the side effects of medication, others are systemic, resulting from community and workplace stigma and the way health and vocational services are organised in Australia;

(r) Most if not all barriers to employment can be overcome with appropriate, sometimes intensive, and creative, specialised vocational assistance. The evidence for this is found in the controlled trials of supported employment in the U.S.A. where $40-60 \%$ of people with severe mental illness obtained competitive employment;

(s) Different approaches (supported employment, vocational rehabilitation, Job Network, clubhouses, social firms, business services) can contribute unique, promising, and established evidence-based ingredients to a broad mix of evidence-based options for people with mental illness;

(t) Policy makers and funding providers can focus on the breadth of ingredients covered in a particular 
region, to ensure that the available funds engage the full spectrum of evidence-based and promising service ingredients including supported education;

(u) Policy makers and funding providers can help by funding a series of demonstration projects aimed at maximising the spectrum of evidence based practices, in comparison to usual services. Different locations (urban vs. rural) and different forms of intersectoral partnerships can be included in demonstration designs;

(v) Public mental health services can adopt a recovery-based approach where for each person, goal orientated strategies link early intervention, relapse prevention, personal goals, treatment goals, housing, education and vocational goals, to specific action plans involving those services;

(w) Accredited training in psychiatric vocational rehabilitation is needed in the following sectors in order of priority: vocational, mental health, disability support, and vocational training and education sectors.

\subsection{Implications for policy development}

The main implication for policy development from this investigation is that existing service types individually offer at most 6 of 11 promising evidence-based ingredients. However, with adjustments to funding structures, accredited workforce training, formal links among different types of vocational services, and with formal links to the public mental health sector, it is possible to provide more effective, intense and continuous forms of psychiatric vocational rehabilitation in Australia than is currently provided. Specific inter-sectoral policies appear needed to broaden mental health care and link it to disability support, vocational services. Mental health care can also be linked to support for other sociallyvalued roles, in order to prevent the life-long social and economic marginalisation associated with mental illness in Australia.

There are several ways this can be achieved. Referrals to vocational services from community mental health staff could be funded separately outside current case-based funding caps, where the costs of ongoing support in employment or education could be shared by the health sector. Alternatively, innovative funding could be made available for services to establish formal links in their local regions which both endure and involve a seamless coordination of health and vocational services to people with mental illness and their families. Such links could range from allocating responsibilities for coordination to individual staff, through to co-locating staff on the business premises of the partner service. In addition, each sector could offer accredited training to the other sector to promote knowledge transfer within and between sectors.

Consultation involving a wide range of stakeholders (including employers and staff of education institutions) is indicated at local, regional and national levels. Such consultation could lead to more innovative systems for providing coordinated mental health care, vocational services and employment opportunities using the latest evidence-based practices.

\subsection{Implications for on-going service development}

A coordinated data collection strategy is needed to assess the effectiveness of existing services and support innovative and evidence-based service development. Common methods and variables are needed across vocational services, similar to the Disability Services Census [174] and which include CRS Australia and the Job Network. Because every funded program can require collection of a different data set, rationalisation of collections may be needed as well as the addition of new mental illness variables to ensure that the data can inform service development for people with mental illness. Other organisations such as the Australian Bureau of Statistics could assist in designing a more independent and rationalised data collection strategy, which can underpin service development and be updated as services and funding structures evolve over time. At present, separate data sets are collected by State Health Departments, HACC, Disability Support providers, Centrelink, FaCS, DEWR and CRS Australia, with no apparent attempt at standardisation or integration to reduce duplication or to increase the pooling capacity of the data collected. 


\subsection{Implications for service consumers and their families}

Effective community mental health care coordinated with vocational services are needed, which have sufficient expertise and resources to help people with mental illness achieve personal recovery goals and restore career pathways. People with mental illness and their families need prospects of social and economic participation. Work, employment and education are more than feasible when assistance is available through evidence-based ingredients, including appropriately intense and continuous assistance. Families and carers can play an active part by helping support a person behind the scenes, without taking away their decision making responsibility, and without providing more assistance than is sought or needed. Families and carers can also assist the vocational team by letting them know when things are not going well, when systemic barriers arise, or when services become uncoordinated. Therefore, families and carers can be included in the development of medium term vocational and recovery plans.

Consumer based organisations can play an active part by providing education and advocacy services and by promoting accredited training in psychiatric vocational rehabilitation. Advocacy and mental health education is an essential service to the community which can be provided independently of vocational and mental health services and warrants financial support by local community, businesses, state, territory, and federal Governments.

\subsection{Priorities for policy makers and funding providers}

Although a range of promising vocational services and programs are available in Australia, the forms in which these are provided are the result of service systems evolving over time. The current organisation of services reflects more upon state-federal funding arrangements and traditional approaches to other types of disability, than to the current needs of people with mental illness and psychiatric disabilities. Policy adjustments are needed to enable Australia to take the lead internationally on psychiatric vocational rehabilitation and supported employment for people with mental illness. Six suggested priorities for policy makers and funding providers are:

(1) shifting towards evidence based practice, by encouraging innovation and by funding demonstration projects to provide a greater range of evidence-based practices;

(2) providing accredited training in psychiatric vocational rehabilitation for the workforces (at 2-3 different levels) in the vocational, disability support, and health sectors;

(3) encouraging inter-sectoral partnerships between the specialised vocational sector and the other sectors by funding local proposals to implement ongoing partnership structures;

(4) removing barriers to services providing more evidence-based assistance to people with mental illness across the working-life;

(5) reforming data collection and data management systems across programs and sectors to ensure common and minimum data sets are collected which enable ongoing evaluation of service effectiveness, efficiency and cost-effectiveness;

(6) inviting service providers and service consumers to help decide how services can be better organised in their local region to most efficiently combine and coordinate services for optimal use of evidencebased practises, and to improve access and outcomes for people with mental illness. 


\section{Acknowledgements}

This report was prepared as a discussion document for the Mental Illness Fellowship of Australia.

This report was prepared with financial support by Professor Harvey Whiteford and the Queensland Centre for Mental Health Research. The Mental Illness Fellowship of Australia (MIFA) assisted with the cost of preparing this report. MIFA's financial contribution was assisted by a grant from Janssen-Cilag. A MIFA advisory group with consumer participation assisted in developing this report. We thank MIFA Board, staff and member organisations for providing valuable input to this report. We also thank Scott Stewart, Paul Nestor, Gerald Graves and Patricia Minnaar for their individual contributions. Helpful comments on earlier drafts of this report were received from Elizabeth Crowther, Margaret Springgay, and Robert Ramjan. We also thank Amanda Greaves of the Division of Occupational Therapy, The University of Queensland, for comments on the potentially complex issues related to ageing and mental illness.

This report shares content (particularly the sections covering barriers to employment and evidence-based ingredients) with a doctoral thesis recently completed by the first author [175].

\section{References}

1. Hughes, R. (1999). Psychosocial rehabilitation: new protocols, ethics and outcomes. International Journal of Mental Health, 28(1), 3-33.

2. Waghorn, G., Chant, D., \& Whiteford, H. (2002). Clinical and non-clinical predictors of vocational recovery for Australians with psychotic disorders. The Journal of Rehabilitation, 68(4), 40-51.

3. Waghorn, G., Chant, D., White, P., \& Whiteford, H. (2004). Delineating disability, labour force participation and employment restrictions among persons with psychosis. Acta Psychiatrica Scandinavica, 109, 279-288.

4. Commonwealth Department of Family and Community Services. (2002). Case Based Funding Trial Evaluation. Interim Report. Canberra: Australian Government. Department of Family and Community Services.

5. Harnois, G., \& Gabriel, P. (2000). Mental health and Work: Impact Issues and Good Practices. Geneva: World Health Organization and International Labour Organisation.

6. Boardman, J., Grove, B., Perkins, R., \& Shepherd, G. (2003). Work and employment for people with psychiatric disabilities. British Journal of Psychiatry, 182, 467-468.

7. Corrigan, P.W. (2003). Beat the stigma: come out of the closet. Psychiatric Services, 54(10), 1313.

8. Whiteford, H.A. \& Buckingham, W.J. (2005). Ten years of mental health service reform in Australia: are we getting it right? Medical Journal of Australia, 182(8), 396-400.

9. Australian Health Ministers. (2003). National Mental Health Plan, 2003-2008. Canberra: Australian Government.

10. Whiteford, H.A., Buckingham, B., \& Manderscheid, R. (2002). Australia's National mental Health Strategy. British Journal of Psychiatry, 180:210-215.

11. Australian Health Ministers (2002). Evaluation of the Second National Mental Health Plan. Canberra: Commonwealth Department of Health and Ageing.

12. Betts, V.T., \& Thornicroft, G. (2001). International Mid-Term Review of the Second National Mental Health Plan for Australia. Canberra: Commonwealth Department of Health and Aged Care.

13. Mental Health Forum on Intersectoral Linkages: (1995). Report to Health, Housing and Community Services Ministers. Canberra: Commonwealth Department of Human Services and Health.

14. Whiteford, H.A. (1994). Intersectoral policy reform is critical to the National Mental Health Strategy. Australian Journal of Public Health, 18, 342-344.

15. Office of the Public Advocate - Queensland. (2004). Annual Report 2003-2004. Brisbane: Queensland Government.

16. Waghorn, G. \& King, R. (1999). Australian trends in vocational rehabilitation for psychiatric disability. Journal of Vocational Rehabilitation, 13(3), 153-163.

17. American Psychiatric Association. (1994). Diagnostic and Statistical Manual of Mental Disorders, (4th Ed.). Washington DC: American Psychiatric Association.

18. World Health Organization. (1993). International Classification of Diseases (ICD-10), (10th Ed.). Geneva: World Health Organization. 
19. Bond, G. (1998). Principles of the Individual Placement and Support model: empirical support. Psychiatric Rehabilitation Journal, 22(1), 11-23.

20. Bond, G. (2004). Supported Employment: evidence for an evidence-based practice. Psychiatric Rehabilitation Journal, 27(4), 345-359.

21. Bond, G.R., Becker, D.R., Drake, R.E., Rapp, C.A., Meisler, N., Lehman, A.F., Bell, M.D., \& Blyler, C.R. (2001). Implementing supported employment as an evidenced based practice. Psychiatric Services, 52, 313322.

22. Bond, G.R., Dietzen, L.L., McGrew, J.H., \& Miller, L.D. (1995). Accelerated entry into supported employment for persons with severe psychiatric disabilities. Rehabilitation Psychology, 40(2), 75-94.

23. Morrow, L., Verins, I., \& Willis, E. (2002). Mental Health and Work Issues and Perspectives. Adelaide: Auseinet - The Australian Network for Promotion, Prevention and Early Intervention for Mental Health.

24. Mathers, C., Vos, T., Stevenson, C. \& Begg, S.J. (2000). The Australian burden of disease study: Measuring the loss of health from diseases, injuries and risk factors. Medical Journal of Australia, 172, 592-596.

25. Organisation of Economic Co-operation and Development (OECD). (2003). Policy Brief. Economic Survey of Australia. Geneva: OECD Economic and Development Review Committee.

26. Organisation of Economic Co-operation and Development. (2003). Ageing Societies and the Looming Pension Crisis - Background Reading. Geneva: OECD Economic and Development Review Committee.

27. Australian Government. (2002). 2002-03 Budget Paper No. 5. Intergenerational Report 2002-03. Canberra: Australian Government.

28. Australian Bureau of Statistics. (1999). Survey of Disability, Ageing and Carers, Australia. Technical Paper. Confidentialized Unit Record File 1998. Canberra: Commonwealth Government.

29. Australian Bureau of Statistics. (1998). Survey of Disability, Ageing and Carers, Australia. Summary of Findings, cat. no. 4430.0. Canberra: Australian Government.

30. Waghorn, G, \& Chant, D. (in press) Employment restrictions among persons with ICD-10 anxiety disorders: characteristics from a population survey. Journal of Anxiety Disorders.

31. Waghorn, G, Chant, D., White, P., \& Whiteford, H. (2005). Disability, employment and work performance among persons with ICD-10 anxiety disorders. Australian and New Zealand Journal of Psychiatry, 39(1), 55-66.

32. Australian Bureau of Statistics. (1998). Mental Health and Wellbeing. Profile of Adults. Cat no. 4326.0. Canberra: Commonwealth Government.

33. Andrews, G., Hall, W., Teesson, M., \& Henderson, S. (1999). The Mental Health of Australians. National Survey of Mental Mealth and Wellbeing. Report 2. Canberra: Mental Health Branch, Commonwealth Department of Health and Aged Care.

34. Henderson, S., Andrews, G. \& Hall, W. (2000). Australia's mental health: an overview of the general population survey, Australian and New Zealand Journal of Psychiatry, 34, 197-205.

35. Meltzer, H., Gill, B., Pettigrew, M. \& Hinds, K. (1995). OPCS Surveys of Psychiatric Morbidity in Great Britain. Report 1. The Prevalence of Psychiatric Morbidity Among Adults Living in Private Households. London: OPCS Social Surveys Division, HMSO.

36. Kessler, R.C., McGonagh, KA, Zhao, S., Nelson, C.B., Hughes, M., Eshleman, S., Wittchen, U. \& Kendler, K.S. (1994). Lifetime and 12-month prevalence of DSM-II-R psychiatric disorders in the United States. Archives of General Psychiatry, 51, 8-19.

37. Andrews, G., \& Hunt, C. (1995). Treatments that work in anxiety disorders. Medical Journal of Australia, 168, 628-634.

38. Barlow, D.H. (Ed). (1993). Clinical Handbook of Psychological Disorders. (2nd Ed.). Chap. 1-5. New York: The Guilford Press.

39. Kessler R., \& Frank R. (1997). The Impact of Psychiatric Disorders on Work Loss Days. Psychological Medicine, 27, 861-873.

40. Kessler, R.C., Greenberg, P.E., Mickelson, K.D., Meneades, L.M., \& Wang, P.S. (2001). The effects of chronic medical conditions on work loss and work cutback. Journal of Occupational \& Environmental Medicine, 43, 218-225.

41. Conti, D.J., \& Burton, W.N. (1994). The economic impact of depression in a workplace. Journal of Occupational Medicine, 36, 983-988. 
42. Claxton, A.J., Chawla, A.J., \& Kennedy, S. (1999). Absenteeism among workers treated for depression. Journal of Occupational and Environmental Medicine, 41(7), 605-11.

43. Simon, G.E., Chisholm, D., Treglia, M., et al. (2002). Course of depression, health services costs, and work productivity in an international primary care study. General Hospital Psychiatry, 24, 328-335

44. Lim, D., Sanderson, K., \& Andrews, G. (2000). Lost productivity among full-time workers with mental disorders. The Journal of Mental Health Policy and Economics, 3, 139-146.

45. Lerner, D., Adler, D.A., Chang, H., et al. (2004). Unemployment, job retention, and productivity loss among employees with depression. Psychiatric Services, 55(12), 1371-1378.

46. Whooley, M.A., Kiefe, C.I., Chesney, M.A., Markovitz, J.H., Matthews K., \& Hulley, S.B. (2002). Depressive symptoms, unemployment and loss of income. Archives of Internal Medicine, 162, 2614-2620.

47. Jablensky, A., McGrath, J., Herrman, H., Castle, D., Gureje, O., Morgan, V., \& Korten, A. (1999). National Survey of Mental Health and Wellbeing. Report 4. People Living with Psychotic Illness: An Australian Study. Canberra: Mental Health Branch. Commonwealth Department of Health and Aged Care.

48. Harding, C.M., Brooks, G.W., Ashikaga, T., Strauss, J.S., \& Breier, A. (1987). The Vermont longitudinal study of persons with severe mental illness, II: Long term outcome of subjects who retrospectively met DSM-III criteria for schizophrenia. American Journal of Psychiatry, 144, 727-735.

49. Lehman, A.F., Goldberg, R., Dixon, L.B., McNary, S., Postrado, L., Hackman, A. \& McDonnell, K. (2002). Improving employment outcomes for persons with severe mental illness. Archives of General Psychiatry, 59(Feb), 165-172.

50. Beard, J.H., Propst, R.N., \& Malamud, T.J. (1982). Fountain House model of psychiatric rehabilitation. Psychosocial Rehabilitation Journal, 5, 47-53.

51. Waghorn, G., \& Chant, D. (unpublished) Labour force activity by people with depression and anxiety disorders: a population level second order analysis. (Manuscript in review).

52. Mueser, K.T., Salyers, M.P., \& Mueser, P.R. (2001). A prospective analysis of work in schizophrenia. Schizophrenia Bulletin, 27, 281-296.

53. Mechanic, D., Bilder, S., \& McAlpine, D.D. (2002). Employment of persons with serious mental illness. Health Affairs, 21(5), 242-249.

54. Waghorn, G., Still, M., Chant, D., \& Whiteford, H. (2004). Specialised supported education for Australians with psychotic disorders. Australian Journal of Social Issues, 39, 443-458.

55. Frost, B., Carr, V., \& Halpin, S. (2002). Employment and Psychosis. Bulletin 3. Low Prevalence Disorder Component of the National Study of Mental Health and Wellbeing. Canberra: Commonwealth Department of Health and Ageing.

56. Carpenter, W.T., \& Strauss, J.S. (1991). The prediction of outcome in schizophrenia IV: eleven-year follow-up of the Washington IPSS cohort. The Journal of Nervous and Mental Disease, 179(9), 517-525.

57. Davidson, L., \& McGlashan, T.H. (1997). The varied outcomes of schizophrenia. Canadian Journal of Psychiatry, 42(1), 34-43.

58. Marengo, J. (1994). Classifying the courses of schizophrenia. Schizophrenia Bulletin, 20(3), 519-536.

59. Mason, P., Harrison, G., Glazebrook, C., Medley, I., Dalkin, T., \& Croudace, T. (1995). Characteristics of outcome in schizophrenia at 13 years. British Journal of Psychiatry, 167, 596-603.

60. Strauss, J.S., Hafez, H., Lieberman, P., \& Harding, C.M. (1985). The course of psychiatric disorder, III: Longitudinal principles. American Journal of Psychiatry, 142, 289-296.

61. Thara, R., Henrietta, M., Joseph, A., Rajkumar, S., \& Eaton, W.W. (1994). Ten-year course of schizophrenia the Madras longitudinal study. Acta Psychiatrica Scandinavica, 90, 329-336.

62. Andresen, R., Oades, L., \& Caputi, P. (2003). The experience of recovery from schizophrenia: towards an empirically validated stage model. Australian and New Zealand Journal of Psychiatry, 37, 586-594.

63. Liberman, R.P., Kopelowicz, A., Ventura, J., \& Gutkind, D. (2002). Operational criteria and factors related to recovery from schizophrenia. International Review of Psychiatry, 14, 256-272.

64. Meddings, S., \& Perkins, R. (2002). What 'getting better' means to staff and users of a rehabilitation service: An exploratory study. Journal of Mental Health, 11, 319-325.

65. Rogers, J.A. (1995). Work is key to recovery. Psychosocial Rehabilitation Journal, 18(4), 5-10. 
66. Auslander, L.A., \& Jeste, D.V. (2002). Perceptions of problems and needs for service among middle aged and elderly outpatients with schizophrenia and related psychotic disorders. Community Mental Health Journal, 38, 391-402.

67. McQuilken, M., Zahniser, J.H., Novak, J., Starks, R.D., Olmos, A., \& Bond, G.R. (2003). The Work Project Survey: Consumer perspectives on work. Journal of Vocational Rehabilitation, 18, 59-68.

68. Rowland, L.A., \& Perkins, R.E. (1988). You can't eat, drink or make love eight hours a day: the value of work in psychiatry - a personal view. Health Trends, 20, 75-79.

69. Fischer, E.P., Shumway, M., \& Owen, R.R. (2002). Priorities of consumers, providers and family members in the treatment of schizophrenia. Psychiatric Services, 53, 724-729.

70. Honey, A. (2000). Psychiatric Vocational Rehabilitation: Where are the customers' views? Psychiatric Rehabilitation Journal, 23(3), 270-279.

71. Honey, A. (2002). Menta Illness and Employment: Personal Perspectives. Thesis. School of Occupation and Leisure Sciences, Faculty of Health Sciences, The University of Sydney.

72. Honey, A. (2003). The impact of mental illness on employment: consumers' perspectives. Work, 20, 267-276.

73. Kirsh, B. (1996). Influences on the process of work integration: the consumer perspective. Canadian Journal of Community Mental Health, 15, 21-37.

74. Kirsh, B. (2000). Work, workers and workplace: a qualitative analysis of narratives of mental health consumers. Journal of Rehabilitation, 66(4), 24-30.

75. Strong, S. (1998). Meaningful work in supportive environments: experiences with the recovery process. The American Journal of Occupational Therapy, 52(1), 31-38.

76. Waghorn, G., \& Lewis, S. (2002). Disclosure of psychiatric disabilities in vocational rehabilitation. Australian Journal of Rehabilitation Counselling, 8, 67-80.

77. Wolfensberger, W. (2000). A brief overview of social role valorization. Mental Retardation, 38(2), 105-123.

78. Laird, M., \& Krown, S. (1991). Evaluation of a transitional employment program. Psychosocial Rehabilitation Journal, 15(1), 3-8.

79. Van Dongen, C.J. (1996). Quality of life and self-esteem in working and non-working persons with mental illness. Community Mental Health Journal, 32(6), 535-548.

80. Bell, M.D., Milstein, R.M., \& Licker, P.H. (1993). Pay as an incentive in work participation by patients with severe mental illness. Hospital and Community Psychiatry, 44, 684-6.

81. Bell, M.D., Lysaker, P.H., \& Milstein, R.M. (1996). Clinical benefits of paid work activity in schizophrenia. Schizophrenia Bulletin, 22(1), 51-67.

82. Rogers, E.S., Anthony, W.A., Cohen, M., \& Davies, R.R. (1997). Prediction of vocational outcome based on clinical and demographic predictors among vocationally ready clients. Community Mental Health Journal, 33(2), 99-112.

83. Lysaker, P.H., Bell, M.D., \& Bioty, M.S. (1995). Cognitive deficits in schizophrenia. Prediction of symptom change for participants in work rehabilitation. Journal of Nervous and Mental Disease, 183(5), 332-336.

84. McDonald, B. (2000). Psychiatric Disability and Vocational Rehabilitation. An Analysis of Outcomes Using the Behaviour and Symptom Identification Scale (BASIS-32). Masters Thesis. Brisbane: The University of Queensland.

85. World Health Organization. (2001). The World Health Report: 2001: Mental Health: New Understanding, New Hope. Geneva: World Health Organization.

86. Spillane, R. (1999). Australian managers' attitudes to mental illness. Journal of Occupational Health and Safety, 15(4), 359-364.

87. McHugo, G.J., Drake, R.E., \& Becker, D.R. (1998). The durability of supported employment effects. Psychiatric Rehabilitation Journal, 22(1), 55-61.

88. Xie, H., Dain, B.J., Becker, D.R., \& Drake, R.E. (1997). Job tenure among people with severe mental illness. Rehabilitation Counseling Bulletin, 40(4), 230-239.

89. Bond, G., Resnick, S.R., Drake, R.E., Xie, H., McHugo, G.J., \& Bebout, R.R. (2001). Does competitive employment improve non-vocational outcomes for people with severe mental illness? Journal of Consulting and Clinical Psychology, 69, 489-501. 
90. Mueser, K.T., Becker, D.R., Torrey, W.C., Xie, H., Bond, G., Drake, R., \& Dain, B. (1997). Work and nonvocational domains of functioning in persons with severe mental illness: a longitudinal analysis. The Journal of Nervous and Mental Disease, 185(7), 419-426.

91. Commonwealth Department of Employment and Workplace Relations. (2004). Job Network Disability Support Pension Pilot: Interim evaluation report. Canberra: Employment Analysis and Evaluation Group, Evaluation and Programme Performance Branch, Australian Government.

92. Mowbray, C., Collins, M., \& Bybee, D. (1999). Supported education for individuals with psychiatric disabilities: Long-term outcomes from an experimental study. Social Work Research, 23, 89-100.

93. Mowbray, C., Bybee, D., \& Collins, M. (2001). Follow-up client satisfaction in a supported education program. Psychiatric Rehabilitaion Journal, 24, 237-247.

94. Mowbray, C., \& Megivern, D. (1999). Higher education and rehabilitation for people with psychiatric disabilities. Journal of Rehabilitation, 65, 31-38.

95. Jaeger, J., Berns, S.M., \& Czobor, P. (2003). The Multidimensional Scale of Independent Functioning: A new instrument for measuring functional disability in psychiatric populations. Schizophrenia Bulletin, 29, 153167.

96. Waghorn, G., Chant, D., \& King, R. (In press-b). Classifying socially-valued role functioning among community residents with schizophrenia or schizoaffective disorder. Journal of Community Psychology.

97. Anthony, W.A. (1994). Characteristics of people with psychiatric disabilities that are predictive of entry into the rehabilitation process and successful employment. Psychosocial Rehabilitation Journal, 17(3), 3-13.

98. Rutman, I.D. (1994). How psychiatric disability expresses itself as a barrier to employment. Psychosocial Rehabilitation Journal, 17(3), 15-35.

99. McGurk, S.R., \& Meltzer, H.Y. (2000). The role of cognition in vocational functioning in schizophrenia. Schizophrenia Research, 45, 175-184.

100. Silverstein, S.M., Schenkel, L.S., Valone, C., \& Nuernberger, S.W. (1998). Cognitive deficits and psychiatric rehabilitation outcomes in schizophrenia. Psychiatric Quarterly, 69(3), 169-191.

101. Tsang, H., Lam, P., Ng, B., \& Leung, O. (2000). Predictors of employment outcome for people with psychiatric disabilities: a review of the literature since the mid 80s. Journal of Rehabilitation, 66(2), 19-31.

102. Bell, M., \& Bryson, G. (2001). Work rehabilitation in schizophrenia: Does cognitive impairment limit improvement? Schizophrenia Bulletin, 27(2), 269-279.

103. Goldberg, R., Lucksted, A., McNary, S., Gold, J., Dixon, L., \& Lehman, A. (2001). Correlates of long-term unemployment among inner-city adults with serious and persistent mental illness. Psychiatric Services, 52(1), 101-103.

104. Lewis, R. (2004). Should cognitive deficit be a diagnostic criterion for schizophrenia? Journal of Psychiatry Neuroscience, 29(2), 102-113.

105. Green, M.F. (1993). Cognitive remediation in schizophrenia: is it time yet? American Journal of Psychiatry, 150(2), 178-187.

106. Green, M.F. (1996). What are the functional consequences of neurocognitive deficits in schizophrenia? American Journal of Psychiatry, 153(3), 321-330.

107. Cole, C., \& McGeary, S. (1991). Evaluating psychological and cognitive factors in the psychiatrically challenged worker. Work, 1(3), 19-31.

108. Anthony, W.A., \& Jansen, M.A. (1984). Predicting the vocational capacity of the chronically mentally ill. American Psychologist, 5, 537-544.

109. Waghorn, G, \& Chant, D. (In press). Employment restrictions among persons with ICD-10 anxiety disorders: characteristics from a population survey. Journal of Anxiety Disorders.

110. Gold, J.M., Goldberg, R.W., McNary, S.W., Dixon, L.B., \& Lehman, A.F. (2002). Cognitive correlates of job tenure among patients with severe mental illness. American Journal of Psychiatry, 159, 1395-1402.

111. McGurk, S.R., \& Mueser, K.T. (2003). Cognitive functioning and employment in severe mental illness. Journal of Nervous and Mental Disease, 191, 789-798.

112. McGurk, S.R., Mueser, K.T., Harvey, P.D., La Puglia, R., \& Marder, J. (2003). Cognitive and symptom predictors of work outcomes for clients with schizophrenia in supported employment. Psychiatric Services, 54, 1129-1135. 
113. Vauth, R., Rusch, N., Wirtz, M., \& Corrigan, P.W. (2004). Does social cognition influence the relation between neurocognitive deficits and vocational functioning in schizophrenia? Psychiatry Research, 128, 155-165.

114. Hoffman, H., Kupper, Z., \& Kunz, B. (1998). Predicting schizophrenic outpatients' behavior by symptomology and social skills. Journal of Nervous and Mental Disease, 186, 214-222.

115. Tsang, W.H., \& Pearson, V. (1996). A conceptual framework for work-related social skills in psychiatric rehabilitation. The Journal of Rehabilitation, 62(3), 61-67.

116. Andreasen, N. (1984). Scale for the Assessment of Positive Symptoms (SAPS). Iowa City: University of Iowa.

117. Andreasen, N.C. (1989). Scale for the Assessment of Negative Symptoms (SANS). British Journal of Psychiatry, 155, 53-58.

118. Smith, T.E., Rio, J., Hull, J.W., Hedayat-Harris, A., Goodman, M., \& Anthony, D.T. (1997). Differential effects of symptoms on rehabilitation and adjustment in people with schizophrenia. Psychiatric Rehabilitation Journal, 21(2), 141-143.

119. Bryson, G., \& Bell, M.D. (2003). Initial and final work performance in schizophrenia: cognitive and symptom predictors. Journal of Nervous and Mental Disease, 191(2), 87-92.

120. Marwaha, S., \& Johnson, S. (2004). Schizophrenia and employment. A review. Social Psychiatry and Psychiatric Epidemiology, 39, 337-349.

121. Hoffman, H., \& Kupper, Z. (1996). Patient dynamics in early stages of vocational rehabilitation: a pilot study. Comprehensive Psychiatry, 37(3), 216-221.

122. Hoffman, H., Kupper, Z., \& Kunz, B. (2001). Vocational Rehabilitation in Schizophrenia. New Findings in Outcome Prediction. In H.D. Brenner, \& W. Boker (Eds.), The Treatment of Schizophrenia, Status and EmergingTrends. Seattle, WA: Hogrefe \& Huber.

123. Kupper, Z., \& Hoffman, H. (2000). Course patterns of psychosocial functioning in schizophrenia patients attending a vocational rehabilitation program. Schizophrenia Bulletin, 26(3), 681-698.

124. Harrison, G., Croudace, T., Mason, P., Glazebrook, C., \& Medley, I. (1996). Predicting the long-term outcome of schizophrenia. Psychological Medicine, 26(4), 697-705.

125. Waghorn, G., Chant, D., \& Whiteford, H. (2003). The strength of self-reported course of illness in predicting vocational recovery for persons with schizophrenia. Journal of Vocational Rehabilitation, 18, 33-41.

126. Hellewell, J.S.E., Kalali, A.H., Langham, S.J., McKellar, J., \& Awad, A.G. (1999). Patient satisfaction and acceptability of long-term treatment with quetiapine. International Journal of Psychiatry in Clinical Practice, 3, 105-113.

127. Bustillo, J.R., Lauriello, J., Horan, W.P., \& Keith, S.J. (2001). The psychosocial treatment of schizophrenia: an update. American Journal of Psychiatry, 158, 163-175.

128. Corrigan, P.W., McCracken, S.G., \& Holmes, E.P. (2001). Motivational interviews as goal assessment for persons with psychiatric disability. Community Mental Health Journal, 37(2), 113-122.

129. Lauriello, J., Bustillo, J., \& Keith, S.J. (1999). A critical review of research on psychosocial treatment of schizophrenia. Biological Psychiatry, 46, 1409-1417.

130. Bell, M., Lysaker, P., \& Bryson, G. (2003). A behavioural intervention to improve work performance in schizophrenia: work behaviour inventory feedback. Journal of Vocational Rehabilitation, 18, 43-50.

131. Anthony, W.A., \& Blanch, A. (1987). Supported employment for persons who are psychiatrically disabled: an historical and conceptual perspective. Psychosocial Rehabilitation Journal, 11(2), 4-23.

132. Blankertz, R., \& Robinson, S. (1996). Adding a vocational focus to mental health rehabilitation. Psychiatric Services, 47, 1216-1222.

133. Becker, D., Drake, R., Farabaugh, A., Bond, G. (1996). Job preferences of clients with severe psychiatric disorders participating in supported employment programs. Psychiatric Services, 47, 1223-1226.

134. Gowdy, E.A., Carlson, L.S., \& Rapp, C.A. (2003). Practices differentiating high-performing from lowperforming supported employment programs. Psychiatric Rehabilitation Journal, 26, 232-239.

135. Evans, J., \& Repper, J. (2000). Employment, social inclusion and mental health. Journal of Psychiatric and Mental Health Nursing, 7, 15-24.

136. Caltruax, D. (2003). Internalized stigma: A barrier to employment for people with mental illness. International Journal of Therapy and Rehabilitation, 10, 539-543. 
137. Long, E., \& Runck, B. (1983). Combating stigma through work for the mentally restored. Hospital and Community Psychiatry, 34(1), 19-20.

138. Murphy, M. (1998). Rejection, stigma, and hope. Psychiatric Rehabilitation Journal, 22, 185-188.

139. Ciardiello, J.A., \& Bingham, W.C. (1982). The career maturity of schizophrenic clients. Rehabilitation Counseling Bulletin, 9, 3-9.

140. Provencher, H., Gregg, R., Mead, S., \& Mueser, K. (2002). The role of work in the recovery of persons with psychiatric disabilities. Psychiatric Rehabilitation Journal, 26, 132-144.

141. Waghorn, G., Chant, D., \& King, R. (2005). Work-related subjective experiences among community residents with schizophrenia or schizoaffective disorder. Australian and New Zealand Journal of Psychiatry, 39(4), 88-99.

142. Mallick, K., Reeves, R., \& Dellario, D. (1998). Barriers to community integration for people with severe and persistent disabilities. Psychiatric Rehabilitation Journal, 22, 175-180.

143. Waghorn, G., Chant, D., \& King, R. (In press-a). Work-related self-efficacy among community residents with psychiatric disabilities. Psychiatric Rehabilitation Journal.

144. Ridgway, P., \& Rapp, C. (1998). The Active Ingredients in Achieving Competitive Employment for People with Psychiatric Disabilities: A Research Synthesis. Lawrence, Kansas: School of Social Welfare, University of Kansas.

145. Corrigan, P., Reedy, P., Thadani, D., \& Ganet, M. (1995). Correlates of participation and completion in a job club for clients with psychiatric disability. Rehabilitation Counseling Bulletin, 39(1), 43-53.

146. Bond, G. (1994). Vocational rehabilitation. In R.P. Liberman (Ed.), The Handbook of Psychiatric Rehabilitation. New York: McMillan.

147. Drake, R.E., McHugo, G.J., Becker, D.R., Anthony, W.A., \& Clark, R.E. (1996). The New Hampshire study of supported employment for people with severe mental illness. Journal of Consulting and Clinical Psychology, 64, 391-399.

148. Drake, R.E., Green, A.I., Mueser, K.T., \& Goldman, H.W. (2003). The history of community mental health treatment and rehabilitation for persons with severe mental illness. Community Mental Health Journal, 39(5), 427-438.

149. Drake, R.E., Becker, D.R., Clark, R.E., \& Mueser, K.T. (1999). Research on the Individual Placement and Support model of supported employment. Psychiatric Quarterly, 70, 289-301.

150. Lucca, A.M., Henry, A.D., Banks, S., Simon, L., \& Page, S. (2004). Evaluation of an Individual Placement and Support model program. Psychiatric Rehabilitation Journal, 27, 251-257.

151. Bond, G.R., Becker, D.R., Drake, R.E., Rapp, C.A., Meisler, N., Lehman, A.F., Bell, M.D., \& Blyler, C.R. (2001). Implementing supported employment as an evidenced based practice. Psychiatric Services, 52, 313 322.

152. Mueser, K.T., Clark, R.E., Haines, M., Drake, R.E., McHugo, G,J., Bond, G.R., Essock, S.M., Becker, D.R., Wolfe, R., \& Swain, K. (2004). The Hartford study of supported employment for persons with severe mental illness. Journal of Consulting and Clinical Psychology, 72, 479-490.

153. Drake, R.E., Becker, D.R., Bond, G.R., \& Mueser, K.T. (2003). A process analysis of integrated and nonintegrated approaches to supported employment. Journal of Vocational Rehabilitation, 18, 51-58.

154. Henry, A.D., Barreira, P., Banks, S., Brown, J., \& McKay, C. (2000). A retrospective study of clubhouse based transitional employment. Psychiatric Rehabilitation Journal, 24, 344-354.

155. Becker, D.R., Bebout, R.R., \& Drake, R.E. (1998). Job preferences of people with severe mental illness: A replication. Psychiatric Rehabilitation Journal, 22 (1), 46-50.

156. Mueser, K.T., Becker, D.R., \& Wolfe, R.S. (2001). Supported employment, job preferences, job tenure and satisfaction. Journal of Mental Health, 10, 411-417.

157. Bilby, R. (1999). Transitional Employment: the most supported of supported employments. The Clubhouse Community Journal, 1, 34-36.

158. Macias, C., Barreira, P., Alden, M., \& Boyd, J. (2001). The ICCD benchmarks for Clubhouses: A practical approach to quality improvement in psychiatric rehabilitation. Psychiatric Services, 52, 207-213.

159. Dougherty, S., Hastie, C., Bernerd, J., Broadhurst, S., \& Marcus, L. (1992). Supported education: a Clubhouse experience. Psychosocial Rehabilitation Journal, 16(2), 91-104. 
160. Liberman, R.P., Hilty, D.M., Drake, R.E., \& Tsang, H.W.H. (2001). Requirements for multidisciplinary teamwork in psychiatric rehabilitation. Psychiatric Services, 52(10), 1331-1342.

161. Calsyn, R.J., Morse, G.A., \& Allen, G. (1999). Predicting the helping alliance with people with a psychiatric disability. Psychiatric Rehabilitation Journal, 22(3), 283-287.

162. Campbell, G., David, C., Jellie, B., Podger, S., \& Raik, H. (1994). Case management. Maintaining the balance. (2nd Ed.). Melbourne: CRS Australia and the Australian Government.

163. Gehrs, M., \& Goering, P. (1994). The relationship between the working alliance and rehabilitation outcomes of schizophrenia. Psychosocial Rehabilitation Journal, 18(2), 43-54.

164. Goldberg, R.W., Rollins, A.L., \& McNary, S.W. (2004). The Working Alliance Inventory, modification and use with people with serious mental illness in a vocational rehabilitation program. Psychiatric Rehabilitation Journal, 27(3), 267-270.

165. Goffman, E. (1963). Stigma. Notes on the Management of Spoiled Identity. Ringwood, Vic: Penguin Books Australia.

166. Davis, C., Martin, G., Kosky, R., \& O'Hanlon, A. (2000). Early Intervention in the Mental Health of Young People: A Literature Review. Adelaide: The Australian Early Intervention Network for Mental Health in Young People.

167. EPPIC (2001). Case Management in Early Psychosis: A Handbook. Melbourne: EPPIC.

168. Kavanagh, D.J., Waghorn, G., Jenner, L., Chant, D.C., Carr, V., Evans, M., Herrman, H., Jablensky, A., \& McGrath, J.J. (2004). Demographic and clinical correlates of comorbid substance use disorders in psychosis: multivariate analyses from an epidemiological sample. Schizophrenia Research, 66, 115-124.

169. National Early Psychosis Project Clinical Guidelines Working Party (1998). Australian Clinical Guidelines for Early Psychosis. Melbourne: National Early Psychosis Project, University of Melbourne.

170. Sainsbury Centre for Mental Health (2003). Briefing 23. A Window of Opportunity: A Practical Guide for Developing Early Intervention in Psychosis Services. London: The Sainsbury Centre for Mental Health.

171. Resnick, S., Rosenheck, R., \& Lehman, A. (2004). An exploratory analysis of correlates of recovery. Psychiatric Services, 55, 540-547.

172. Rickwood, D. (2004). Pathways of Recovery: Preventing Relapse. Canberra: Department of Health and Ageing.

173. Bond, G., Salyers, M., Rollins, A., Rapp, C., \& Zipple, A. (2004). How evidence-based practices contribute to community integration. Community Mental Health Journal, 40, 569-588.

174. Australian Government. (2002). Australian Government Disability Services Census. Canberra: Australian Government, Department of Family and Community Services.

175. Waghorn, G. (2005). Work-Related Subjective Experiences, Work-Related Self-Efficacy and Vocational Status Among Urban Residents with Schizophrenia or Schizoaffective Disorder. Doctoral Thesis. Brisbane: The Department of Psychiatry, The University of Queensland. 